FINAL REPORT

U.S. Department of Energy

\title{
Colloidal Agglomerates in TANK SLUdge: \\ IMPACT ON WASTE Processing
}

\author{
Lead Principal Investigator \\ Dr. Joel M. Tingey
}

Pacific Northwest National Laboratory

\section{Co-Investigator}

Professor John D. Berg

University of Washington

Department of Chemical Engineering

\section{Contributors}

KD Keefer (PNNL)

AS Lea (PNNL)

DR Rector (PNNL)

JW Virden (PNNL)

S Stenkamp (University of Washington)

Project Number: 54628

Grant Number: DE-FG07-96ERxxxxx

Grant Project Officers:

Project Duration: (FY96-FY99) 


\section{Executive Summary}

Disposal of millions of gallons of existing radioactive wastes in underground storage tanks is a major remediation activity for the United States Department of Energy. These wastes include a substantial volume of insoluble sludges consisting of submicron colloidal particles. Processing these sludges under the proposed processing conditions presents unique challenges in retrieval, transport, separation, and solidification of these waste streams. Depending on processing conditions, these colloidal particles can form agglomerated networks having high viscosities that could clog transfer lines or produce high volumes of low-density sediments that interfere with solid-liquid separations. Under different conditions, these particles can be dispersed to form very fine suspended particles that do not settle. Given the wide range of waste chemistries present at Department of Energy sites, it is impractical to measure the properties of all treatment procedures. The underlying principles of colloid chemistry and physics were studied to provide data that would make it possible to predict and eventually control the physical properties of sludge suspensions and sediment layers in tank wastes and other waste processing streams.

Proposed tank processing strategies include retrieval, transport, and solid-liquid separations in basic ( $\mathrm{pH} 10$ to 14$)$, high ionic strength $(0.1$ to $1.0 \mathrm{M})$ salt solutions. The effect of salt concentration, ionic strength, and salt composition on the physical properties such as viscosity, agglomerate size, and sedimentation of model suspensions containing mixtures of one or two of the major components found in actual wastes have been measured to understand how agglomeration influences processing. Property models developed from theory and experiment on these simple suspensions are then applied to explain the results obtained on actual wastes.

Transmission electron microscopy of actual Hanford tank wastes demonstrates that most sludge consist largely of submicron $\left(<10^{-6} \mathrm{~m}\right)$ primary particles of hydrated oxides of $\mathrm{Al}, \mathrm{Fe}, \mathrm{U}$, $\mathrm{Zr}, \mathrm{Mn}, \mathrm{Cr}, \mathrm{Ni}$, and Ti. Small particles of insoluble salts such as apatite $\mathrm{Ca}_{5}\left(\mathrm{PO}_{4}\right)_{3} \mathrm{OH}$, uranium phosphate, aluminum phosphate, bismuth phosphate, and the zeolite cancrinite are also present. 
These submicron particles are in contact with highly basic $(\mathrm{pH} 10-14)$, high ionic strength (0.1-10 M) salt solutions (mainly $\mathrm{NaNO}_{3}$ and $\mathrm{NaOH}$ ). Static light scattering measurements on simple surrogates and actual waste indicate that in such solutions, the particles are attracted to each other resulting in extensive aggregation to from fractal agglomerates. This structure has an enormous impact on slurry properties because fractal objects occupy much more space than dense objects at the same solids loading.

Large variability is observed in the slurry properties of the waste in the tanks. This variability is also observed within an individual tank. In spite of this variability, the experimental results obtained for simple surrogate systems are comparable to actual tank waste samples under similar conditions. Depending on the extent of agglomeration and solids loading, slurry viscosities can vary by over five orders of magnitude. To achieve desired viscosities for retrieval and transport by dilution only, these sludges require 20 -fold dilution, producing enormous quantities of wastes.

Sedimentation experiments were performed at varying solids loadings, $\mathrm{pH}$, salt concentration, salt type, and applied pressure to determine the impact of chemical processing on the sediment densities that can be obtained during settle-decant processes. Primary particle and agglomerate size can influence sedimentation rates by over three orders magnitude. Final sediment densities ranging from 1 to 8 volume percent are common in Hanford tank wastes. This means that particulate layers occupy large volumes during sludge washing and leaching and that the volume occupied by these sediment layers is predominantly interstitial water that is not removed during solid-liquid separations. The solids loading in sediment layers is highly dependent on the degree of agglomeration and the interparticle interaction potential. Packing of individual particles can be highly efficient (up to 50 volume percent) for dispersed systems (low $\mathrm{pH}$ and low ionic strength). For agglomerated systems, sediment densities are much lower (4 volume percent); therefore, the agglomerated sludge occupies over 10 times more space and 
contains 24 times the volume of non-removable interstitial liquids than the sediment formed from the dispersed sludge, having an adverse impact on the efficiency of solids-liquids separations.

Sediment densities can be increased by weakening interparticle interactions. Manipulation of such forces could be used to improve tank utilization and the efficiency of solidliquid separations during steps such as sludge washing and leaching. In the high-salt regime of most tank wastes, sediment densities first decrease, then increase with salt content because of the interplay of electrical double layer and hydration forces. The presence of calcium and other divalent cations is particularly effective in promoting sediment compression. Sediment densities are also significantly impacted by $\mathrm{pH}$. The lowest sediment density (4 vol\%) is observed near the isoelectric point of the particle with the sediment density increasing on either side of the isoelectric point (up to $50 \mathrm{vol} \%$ ).

Primary particle size distributions have been determined using transmission electron microscopy, and agglomerate size distributions have been estimated using static light scattering on dilute suspensions. Based on these measurements and theoretical values for fractal dimensions, sediment densities have been predicted to within about $20 \%$ for single component systems as well as actual sludges. Solids loadings at which slurry viscosities will exceed the desired maximum for tank waste retrieval and transport have also been predicted to within about $30 \%$, and sedimentation velocities in settle-decant operations have been predicted to within a factor of around 5. In terms of general trends, the least tractable slurries are those containing the smallest primary particles (10 nm particles are common in actual tank sludges), the largest agglomerate sizes, and the smallest fractal dimensions. Such slurries can have viscosities in excess of $10,000 \mathrm{cP}$ at solids loadings as low as $1 \mathrm{vol} \%$. At the other extreme, slurries containing primary particles larger than $10 \mathrm{ìm}$ can exhibit viscosities below $100 \mathrm{cP}$ even at $30 \mathrm{vol} \%$.

Work performed on this project at the University of Washington was reported in a dissertation prepared by Victoria Sus an Stenkamp as partial fulfillment of the requirements for a $\mathrm{PhD}$. in Chemical Engineering. This research was directed at understanding how organic 
molecules called steric stabilizers function in the high salt regime of tank wastes. Once the factors controlling steric stabilization at high ionic strength are understood, it may be possible to manipulate sludge behavior with low concentrations of such organic additives. Triblock copolymers were used as steric stabilizers on core particles of polystyrene la tex with sulfate functional groups that allow the polymers to anchor to the core particle. The impacts of polymer molecular weight, salt concentration, and salt type on steric stabilization were investigated. Increasing the molecular weight of the polymer causes an increase in steric stabilization. A small increase in molecular weight from an 11-monomer-length polymer to a 13-monomer-length polymer, showed dramatic increases in stabilization of the particle. This increase may be due to ion binding of the salt in the longer polymer that is not possible in the shorter polymer. Results obtained from the 13-monomer-length polymer indicate that order of stabilization in high ionic strength solutions is $\mathrm{BaCl}_{2}>\mathrm{NaNO}_{3}, \mathrm{LiCl}, \mathrm{NaCl}, \mathrm{KCl}>\mathrm{KSCN}, \mathrm{KNO}_{3}$. X-ray photoelectron spectroscopy (XPS) and RAMAN spectroscopy were performed on this same system in both KSCN and $\mathrm{BaCl}_{2}$ to understand the processes that cause stabilization to occur in $\mathrm{BaCl}_{2}$ and not in KSCN solutions. The results from these studies indicated that the Madelung shift (a constant representing the sum of the mutual potential coulombic attraction energy of all the ions in a lattice) correlates with the order in which the anions induce restabilization of these particles. It was also observed that $\mathrm{BaCl}_{2}$ tends to weaken the ether oxygen bonds in the polyethylene oxide more than the $\mathrm{KSCN}$, but the conformation of the polyethylene oxide is the same in both the $\mathrm{KSCN}$ and $\mathrm{BaCl}_{2}$ solutions.

The results obtained from this research can support several science and technology needs at the Hanford Site, Savannah River Site, Oak Ridge National Laboratory, and Idaho National Engineering and Environmental Laboratory. Of particular interest to these sites are methods to improve solid/liquid separations and strategies to prevent transport line plugging. Expertise, data, and capabilities developed as part of this project have supported Hanford tank waste retrieval and transport projects, Hanford tank waste safety projects, characterization of sludges from Hanford's 
spent nuclear fuel basins, and development of physical characterization capabilities at both the Hanford and Oak Ridge analytical laboratories.

\section{Research Objective}

Insoluble colloidal sludges in hazardous waste streams such as tank wastes can pose serious problems for waste processing, interfering with retrieval, transport, separation, and solidification processes. Properties of sediment layers and sludge suspensions such as slurry viscosities, sedimentation rates, and final sediment densities can vary by orders of magnitude depending on the particle types present, the degree to which the particles agglomerate, and processing parameters such as shear rates, $\mathrm{pH}$, salt content, and temperature. The objectives of this research are to

- understand the factors controlling the nature and extent of colloidal agglomeration under expected waste processing conditions

- determine how agglomeration phenomena influence physical properties relevant to waste processing including rheology, sedimentation, and filtration

- develop strategies for optimizing processing conditions via control of agglomeration phenomena.

Complex radioactive mixtures of supernatant liquids (typically highly basic salt solutions), saltcake (consisting primarily of sodium nitrate and nitrite), and insoluble sludges consisting of submicron colloidal particles are stored at various locations on U.S. Department of Energy (DOE) sites. Over 100 million gallons of this radioactive waste is stored in underground tanks. The largest quantity and most complex mixtures of these radioactive wastes are located at the Hanford Site. Although the radioactivity is the primary concern in remediating these wastes, handling and processing the radioactive insoluble sludges provides a major technical challenge. Treatment and ultimate disposal of these wastes will require that these insoluble sludges be dispersed in aqueous solutions for retrieval and transport, separated from the liquid, and converted to a stable waste form. These tank wastes will be partitioned into high-level and lowlevel fractions because of the high cost of high-level waste vitrification and geologic disposal. 
The low-level fraction will be processed to remove ${ }^{137} \mathrm{Cs}$ (and possibly other radionuclides) and will then be immobilized in a glass matrix and disposed of by shallow burial on site. The highlevel fraction will be immobilized in a borosilicate glass matrix, and the resulting glass canisters will be disposed of in a geologic repository. The maximum possible solids loading in each of the processing steps and the final waste forms are desired to minimize waste volumes.

The ability to maximize the solids loading and effectively process the wastes is dependent upon understanding and properly manipulating the colloidal behavior in these waste streams. Depending on processing conditions, these colloidal particles can form agglomerated networks having high viscosities that could clog transfer lines or produce high volumes of lowdensity sediments that interfere with solid-liquid separations such as settle-decant operations during sludge washing and leaching. Under different conditions, the particles can be dispersed to form very fine suspended particles that do not settle during settle-decant operations. These suspended particles may foul and contaminate downstream components such as ion exchangers or filtration systems. The formation and properties of viscous sludge layers also contribute significantly to the retention and periodic release of potentially flammable or explosive gas mixtures in some Hanford tanks. Colloidal agglomerates are also important to the processing and remediation of other waste streams, including the sludges present in fuel storage basins such as the K-Basins at Hanford.

Given the wide range of waste chemistries present at Hanford and other DOE sites, it is impractical to measure the properties of all possible sludge compositions under all potential processing conditions to design effective treatment procedures. Instead, a framework needs to be established to predict sludge property trends on a sound scientific basis. The underlying principles of colloid chemistry and physics provide such a framework, allowing us to predict and eventually control the physical properties of sludge suspensions and sediment layers in tank wastes and other waste processing streams. 


\section{Methods and Results}

A combined experimental and theoretical approach was used to study agglomeration phenomena in relation to waste processing conditions. Research activities focused on understanding and measuring interparticle forces, agglomerate structures, and physical properties impacted by agglomerate structures. From the data obtained by these measurements and understanding the underlying principles of colloid chemistry and physics the physical properties of sludge suspensions and sediment layers in tank wastes and other waste processing streams can be predicted and eventually controlled.

This project provides connections between insights regarding colloidal suspensions on multiple length scales: atomic interactions leading to agglomerate structures followed by macroscopic physical properties and resulting in deployment in an engineering process. The connections between basic science at the particle level to macroscopic properties of interest to process design engineers is critical to the development of technically defensible processing strategies.

Due to the complexity of actual sludge, the majority of the experimental work was performed on well-defined suspensions of components known to be present in tank wastes, which have been shown to exhibit properties similar to those of actual wastes ${ }^{1}$. Transmission Electron Microscopy (TEM) indicates that many insoluble solids in these tanks include complex agglomerates of submicron primary particles of oxides and hydroxides such as $\mathrm{Fe}(\mathrm{OH})_{3}$, boehmite $(\mathrm{AlOOH})$, and gibbsite $\left(\mathrm{Al}(\mathrm{OH})_{3}\right)^{2}$; therefore, simple colloidal systems of these components and $\mathrm{ZrO}_{2}$ and apatite $\left(\mathrm{Ca}_{5}\left(\mathrm{PO}_{4}\right)_{3} \mathrm{OH}\right)$, were prepared, and agglomeration, sedimentation, and rheology measurements have been made on both single component and mixed suspensions of these particles. These materials encompass primary particle sizes spanning the 0.01 to $10 \mu \mathrm{m}$ size range of greatest concern for sludge processing. 


\section{$\underline{\text { Experimental Methods }}$}

Suspensions were prepared to systematic ally vary key parameters such as primary particle size, $\mathrm{pH}$, salt content, solids loading, temperature, and solution agitation levels with an emphasis on conditions that replicate supernatant liquids present in existing tanks (such as high-salt, high$\mathrm{pH})$. Simple surrogate systems of colloidal suspensions containing boehmite $(\mathrm{AlOOH}), \mathrm{Fe}(\mathrm{OH})_{3}$, gibbsite $\left(\mathrm{Al}(\mathrm{OH})_{3}\right), \mathrm{ZrO}_{2}$, and apatite $\left(\mathrm{Ca}_{5}\left(\mathrm{PO}_{4}\right)_{3} \mathrm{OH}\right)$ have been shown to exhibit properties similar to actual tank waste samples under similar conditions. Tank wastes usually contain mixtures of primary particle sizes and compositions rather than being monodisperse; therefore, mixed particle surrogates were also prepared. These mixed simulants included mixtures of large primary particles plus hard fractal agglomerates $(1.3 \mu \mathrm{m}$ gibbsite $+1.6 \mu \mathrm{m}$ agglomerates of $\mathrm{Fe}(\mathrm{OH})_{3}$ ), mixtures of "soft" agglomerates of large and small primary particles (heated mixtures of $1.3 \mu \mathrm{m}$ gibbsite and $0.05 \mu \mathrm{m}$ boehmite), and mixtures containing similar primary particle sizes but different interparticle interaction potentials (boehmite + apatite).

The suspensions were prepared by adding a known mass of powder to a known volume of salt solution at the desired $\mathrm{pH}$. The total volume is calculated by adding the volume of salt solution to the volume of powder that is calculated from the density and mass of the powder. This calculation assumes that none of the powder dissolves in the salt solution and that the volumes are additive. The resulting suspensions are stirred and the $\mathrm{pH}$ adjusted back to the desired $\mathrm{pH}$ with concentrated $\mathrm{NaOH}$ or concentrated acid with the same anion as is present in the salt solution. The suspension is sonicated at greater than $50 \mathrm{~W}$ for 1 minute. The sample is then stirred and the $\mathrm{pH}$ adjusted. A final sonication at greater than $50 \mathrm{~W}$ for 1 minute is completed, and the $\mathrm{pH}$ is once again adjusted while the suspension is stirred. The sample is then stirred until the analyses begin. All analyses are begun within 24 hours of preparation of the samples unless otherwise stated. 
Sedimentation rate and final sediment bed density were measured as a function of $\mathrm{pH}$, ionic strength, solids loading, and salt type. Stirred suspensions prepared as described above were poured into clear graduated cylinders, and sediment height was monitored as a function of time. Sediment height is the distance from the bottom of the suspension column to the interface between the clear supernatant and the cloudy suspension. Under the force of gravity, the solids in the suspension sink to the bottom of the cylinder forming a sludge layer and a clear supernatant layer. The final sediment bed volume is measured after no significant change in the height of this sludge layer is observed over 24 hours. The sediment density is then determined by dividing the volume of solids in the suspension by the final sediment bed volume.

Viscosity studies were also conducted on a variety of suspensions as a function of $\mathrm{pH}$, ionic strength, and solids loading. The well-stirred suspension was placed in the rheometer and measurements were made shortly after adding the suspension to minimize settling effects. Viscosity of these suspensions was calculated from a scan of shear stress as a function of shear rate. These measurements were made on a Bohlin VOR rheometer over a shear rate range from 0 to $12001 / \mathrm{s}$. These slurries were prepared as described above.

Zeta potential was also measured on a variety of dispersions in high-salt solutions. Zeta potential measurement of colloidal dispersions at high salt concentrations is a new and unexplored scientific area with many reported departures from expected theory, including elimination of the isoelectric point and restabilization of colloidal particles with adsorbed surfactants. Zeta potential is experimentally determined by measuring the motion of particles in solution under an applied electric field. Traditionally, these measurements are performed at low ionic concentrations due to experimental difficulties at high salt concentrations. These measurements are still problematic and require attention to establishing the proper experimental conditions (voltage, frequency and sample count rate) and common sense to interpret the results. The high conductivity of the concentrated salt solutions limit the voltage and current that can be applied to the solution while still imparting movement of the particles due to the applied electric 
field. If too high a voltage is applied water is broken down to hydrogen and oxygen at the anode and cathode respectively. If too high a current is applied, heating of the sample occurs creating fluid-flow gradients that disturb the measurement of particle motion.

To complement the zeta potential measurements, a surface force apparatus was used to determine the impact of high salt solutions on the short-range hydration forces in colloidal systems. Surface Force Apparatuses (SFAs) directly measure the static and dynamic forces between surfaces. It can also be used to measure the refractive index of the medium between the surfaces, molecular orientations in thing films, adsorption isotherms, capillary condensation, surface deformations arising from surface forces, dynamic interactions such as viscoelastic and frictional forces, and other time-dependent phenomena in real time. Mica surfaces were coated with tri-block copolymers prepared at varying salt concentrations. The thickness of the coatings was varied from 450 to 500 angstroms. The shapes of the interacting surfaces and the separation between the surfaces are measured by analyzing the optical interference fringes produced when white light passes normally through the two surfaces. Dynamic measurements are conducted with surfaces in motion by vibrating the piezoelectric crystal supporting the upper surface.

Primary particle sizes and particle morphologies were measured by Transmission electron microscopy (TEM). Agglomerate sizes were characterized using commercial particle-size analysis equipment. The systems utilized span a range of measurement methods including light attenuation, photon correlation spectroscopy and Fraunhofer diffraction, sedimentation rate methods, and electrophoretic mobility. These methods are easy to use, provide rapid feedback, and can be used on radioactive samples. However, these methods do not distinguish between dense and fractal particles. The most powerful methods for determining agglomerate structures are scattering methods including small-angle X-ray scattering (SAXS), small-angle neutron scattering (SANS), and dynamic light scattering techniques; therefore, a SAXS system was developed to measure agglomerate size in surrogate systems in high-salt, high-pH solutions.

\section{Simulation Methodology}


The macroscopic physical properties for a particular colloidal particle gel depend on both the gel microstructure and the interparticle forces. One example of a gel property is the compressive yield stress, $\mathrm{P}_{\mathrm{y}}(\phi)$, which is a measure of the force required to compact a gel network to a specified volume fraction, $\phi$. The compressive yield stress controls both the final sediment height of a colloidal suspension and the rate at which the sediment compresses to reach that final height. Simulations are used to calculate the compressive yield stress as a function of gel microstructure and interparticle forces.

Particle gel formation and gel compression are simulated using the Brownian dynamics method. Consider a system of $\mathrm{N}$ spherical particles, with diameter $\sigma$ and mass $\mathrm{m}$, contained in a cubic simulation cell with periodic boundary conditions. If we neglect many-body hydrodynamics and consider only Stokes drag on each particle, the translational motion is described by the Langevin equation

$$
m \frac{d v_{i}(t)}{d t}=-\zeta v_{i}(t)+F_{i}(t)+F_{i}^{R}(t)
$$

where $\zeta$ is the Stokes friction coefficient

$$
\zeta=3 \pi \eta \sigma
$$

$F_{i}(t)$ are the interparticle forces and $F_{i}^{R}(t)$ is a random component with Gaussian distribution. The momenta decay rapidly and an update algorithm can be written as

$$
\Delta r(\Delta t)=\zeta^{-1} F_{i} \Delta t+R_{i}(D, \Delta t) ; \quad i=1,3 N
$$

where $\Delta \mathrm{r}_{\mathrm{i}}(\Delta \mathrm{t})$ is the overall change in particle position in direction i during timestep $\Delta \mathrm{t}$, and $R_{i}(D, \Delta t)$ is the random translational displacement of a particle with diffusion coefficient $D$ during timestep $\Delta \mathrm{t}$. A similar equation is developed for the rotational motion of each particle.

Most Brownian dynamics simulations are performed with interparticle interaction potentials based on the distance between particle centers. The disadvantage for using these types 
of potentials in describing a compressive load bearing gel network is that the bonded particles are free to move around the circumference of their partners. Rigidity is provided by specifying an interaction potential that consists of both a particle core potential and a surface bonding interaction.

$$
\phi\left(r_{i j}, b_{i j}\right)=\phi_{c}\left(r_{i j}\right)+\phi_{s}\left(b_{i j}\right)
$$

The particle core is represented by a steeply repulsive spherical potential

$$
\phi_{c}\left(r_{i j}\right)=\varepsilon\left(\frac{\sigma}{r_{i j}}\right)^{n}
$$

where $r_{i j}=r_{i}-r_{j}$ is the interparticle distance and where in this work we have chosen $n=36$ which is sufficiently steep to be a good approximation to a hard sphere without causing numerical problems.

Surface bonding is represented by an interaction potential that is switched on when the particles are within a specified cutoff distance. Only one bond may be formed per particle pair and this is defined by an interaction between bond nodes created on the 'surface' of each particle at $r=\sigma / 2$. These nodes are initially formed on a line joining the particle centers but the alignment is rapidly destroyed by subsequent relative motion. The surface interaction potential is

$$
\phi_{s}\left(b_{i j}\right)=\frac{\varepsilon_{1}}{b_{i j}^{2}}-\frac{\varepsilon_{2}}{b_{i j}}
$$

where $b_{i j}$ is the distance between surface nodes. The attractive term is proportional to the inverse of the separation distance, which is similar to the Derjaguin approximation for two spheres at small separation. This allows comparison of results with experimental results for particles with a known Hamaker constant. The ratio $\varepsilon_{1} / \varepsilon_{2}$ determines the shape of the potential and the location of the minimum. The value of $\varepsilon_{2}$ (for a fixed ratio) determines the depth of the potential well. The surface bond is destroyed when the separation distance between surface nodes exceeds a specified cutoff distance. If the minimum surface separation between particles is still within the 
cutoff distance, a new surface bond is formed. For these simulations the parameters have been adjusted so that the potential minimum is located at $b_{i j}=0.01 \sigma$ and the cutoff distance is $b_{i j}=$ $0.2 \sigma$.

Compression of the gel network is simulated by using a scaling factor, s, for length scales in the z-direction. For example, the center-to-center particle distance becomes

$$
r_{i j}^{2}=r_{x}^{2}+r_{y}^{2}+s^{2} r_{z}^{2}
$$

where $r_{x}, r_{y}$, and $r_{z}$ are the $x-, y-$, and z-components of $r_{i j}$. The surface node separation distance is similar except that the z-component of each surface node location with respect to the particle center is not affected by the scaling factor.

The compression simulation is performed using a repeating sequence of two stages, a compression stage and an equilibrium stage. During the compression stage the scaling factor is gradually reduced in a linear fashion. The rate of reduction depends on a variety of factors, including the potential well depth and temperature. After a period of time, the scaling factor is held constant and the system is allowed to reach equilibrium. The approach to equilibrium is monitored using the calculated values of the stress tensor. Once the system has reached equilibrium, quantities such as the stress tensor and the coordination number are calculated for that volume fraction.

$$
\sigma_{\alpha \beta}=\rho k_{B} T-\frac{1}{V} \sum_{j>1}^{N} \sum_{i=1}^{N-1} r_{\alpha i j} F_{\beta i j}
$$

where the subscripts $\alpha$ and $\beta$ denote the Cartesian components of vector quantities. The assumption made here is that the multi-particle hydrodynamic interactions are negligible compared to the contributions from the particle gel network.

This simulation methodology provides a direct connection between the microscopic interparticle interaction potential, which is not directly measurable, and the macroscopic gel property compressive yield stress, which can be obtained from sedimentation experiments. By 
varying the interparticle potential and comparing the change in the compressive yie ld stress with experimental results, we may be able to infer the effect of changes in solution chemistry on the interparticle potential.

\section{$\underline{\text { Results }}$}

The properties of particulate suspensions are sensitive to many factors including the size shape, surface chemistry, and solids loading of the particles, as well as solution compositions (particularly $\mathrm{pH}$ and salt content). The results obtained in this project provide insight in how to define tank waste processing windows based on accurate predictions of how properties should vary depending on particle distributions and slurry chemistry. This report summarizes the current state of knowledge regarding the major types of particles present in Hanford tank wastes, how these particles are expected to interact with each other, and how slurries are expected to behave as a function of particle types and solution conditions.

\section{Particles and Agglomerates in Actual Tank Sludge}

The first step in predicting sludge properties involves determining what particle types comprise the settled materials. If large $\left(>10^{-4} \mathrm{~m}\right)$ particles are present, sludges can behave like sand, being hard to suspend and producing low slurry viscosities except at very high solids loadings. However, if submicron $\left(<10^{-6} \mathrm{~m}\right)$ particles are present, viscous particulate networks or non-sedimenting suspensions can form. Transmission electron microscopy (TEM) has been used to resolve what insoluble particle types are present in different tank sludges ${ }^{3}$. TEM can provide atomic $\left(10^{-10} \mathrm{~m}\right)$ resolution images of even the smallest sludge particles, identify crystal structures for individual particles via electron diffraction, and provide compositional information on features as small as $10^{-9} \mathrm{~m}$ using energy dispersive $\mathrm{x}$-ray spectroscopy (EDS).

Given the compositional diversity of tank wastes, TEM and X-ray analyses show that surprisingly few major phases are present. Hanford sludges consist largely of submicron 
$\left(<10^{-6} \mathrm{~m}\right)$ primary particles of hydrated oxides of $\mathrm{Al}, \mathrm{Fe}, \mathrm{U}, \mathrm{Zr}, \mathrm{Mn}, \mathrm{Cr}, \mathrm{Ni}$, and Ti. Mixed oxides (Fe-Mn, Fe-Ni, Fe-Cr, Al-Cr) are sometimes observed. The aluminum-containing precipitates represent the largest fraction of the insoluble material present and include phases such as gibbsite $\left(\mathrm{Al}(\mathrm{OH})_{3}\right)$ and boehmite $(\mathrm{AlOOH})$. Small particles of insoluble phosphates such as apatite $\left(\mathrm{Ca}_{5}\left(\mathrm{PO}_{4}\right)_{3} \mathrm{OH}\right)$, uranium phosphate, aluminum phosphate, and bismuth phosphate are prevalent in some waste types. Much of the silicon in tank wastes appears to be in zeolites such as cancrinite $\left(\mathrm{Na}_{8} \mathrm{Al}_{6} \mathrm{Si}_{6} \mathrm{O}_{24} \mathrm{CO}_{3}-3 \mathrm{H}_{2} 0\right)$, amorphous aluminosilicates, clay minerals, and sand. Bismuth-rich tanks contain high concentrations of phases such as $\mathrm{Fe}_{2} \mathrm{Bi}\left(\mathrm{SiO}_{4}\right)_{2} \mathrm{OH}$ and $\mathrm{Bi}_{2} \mathrm{Fe}_{4} \mathrm{O}_{9}$. In many situations the primary particles of a dispersed system tend to associate into larger structures known as agglomerates. Agglomerates can further associate to form larger structures called flocs. Primary particle and agglomerate sizes observed to date in tank wastes span five orders of magnitude as is shown in Figure 1. However, size ranges for each individual phase tend to be narrow. The smallest particles are hydrous oxides such as $\mathrm{ZrO}_{2}$ and $\mathrm{FeOOH}$ that are only 3 to $6 \mathrm{~nm}$ in diameter. Next in size are boehmite and apatite, which are present as plates or as needles ranging from $100 \mathrm{~nm}\left(10^{-7} \mathrm{~m}\right)$ to $1 \mu \mathrm{m}\left(10^{-6} \mathrm{~m}\right)$ in length. These submircron particles form agglomerates that are typically $1-10 \mu \mathrm{m}$ in diameter, but can be as large as $100 \mu \mathrm{m}$. The largest primary particles seen to date are isolated crystals of gibbsite $\left(\mathrm{Al}(\mathrm{OH})_{3}\right)$ and uranium phosphate in Hanford tank 241-C-112, which can exceed $20 \mu \mathrm{m}$ in size.

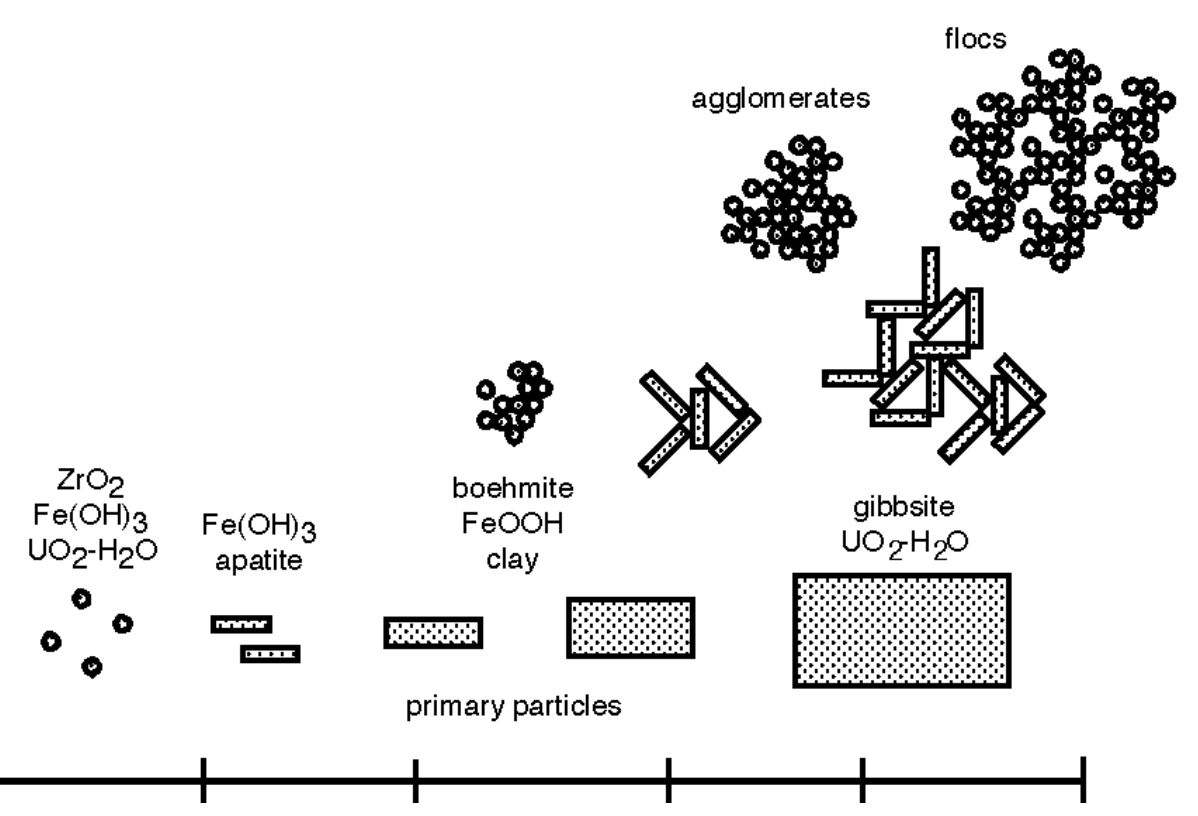


Figure 1. Particle Types in Tank Sludge

In existing tanks, and in most proposed tank processing schemes, the particles are in contact with highly basic ( $\mathrm{pH} 10-14)$, high ionic strength (0.1-10 M) salt solutions (mainly $\mathrm{NaNO}_{3}$ and $\mathrm{NaOH}$ ). In such solutions, the electrical double layers associated with charged sites in particle surfaces collapse, and the electrostatic repulsions that can disperse particles of like charge disappear. Therefore, under most tank waste processing conditions, the particles comprising most sludges are predicted to be attracted to each other (van der Waals attraction dominates) resulting in extensive particle agglomeration.

Primary particle size distributions within a given tank can be estimated from combinations of TEM images, waste compositions, and processing histories; however, these distributions will likely change during processing. Particles can dissolve or precipitate in response to changes in solution conditions such as temperature or $\mathrm{pH}$. For example, precipitation of aluminate gels due to cooling has plugged pipes connecting Hanford tanks ${ }^{4}$. Although particle concentrations and morphologies are not always fixed, most sludges consist of 1 to $100 \mu \mathrm{m}$ agglomerates of submicron primary particles. Even in tanks that contain large primary particles, such as Hanford Tank 241-C-112, less than $50 \%$ of the solid volume consists of primary particles larger than $1 \mu \mathrm{m}$.

Given the complexity and radioactivity of actual tank waste sludge, most of the work performed in this project involves examining model suspensions containing mixtures of one or two of the major components found in actual wastes and studying how agglomeration influences 
physical properties such as viscosity and sedimentation. Experimental results on the simple systems are rationalized using theoretical models that describe particulate suspensions. Property models developed from theory and experiment on the simple suspensions are then applied to explain the limited results that have been obtained on actual tank wastes.

Rheological and physical data have been obtained on samples from 17 single-shell and 10 double-shell tanks. Many of these samples were processed to simulate the baseline processes proposed for ultimate disposal of these tank wastes. Physical properties and rheology have also been measured on these process samples. The results from these analyses have been compared with the results obtained on the simple systems used in this project. Large variability is observed in the properties of the waste in the tanks. This variability is also observed within an individual tank. In spite of this variability, the experimental results obtained for simple surrogate systems are comparable to actual tank waste samples under similar conditions.

\section{Dispersion and Agglomeration of Simulated Wastes}

Physical properties of tank sludges such as sedimentation and rheology depend on the extent to which submicron primary particles are dispersed or agglomerated. Interparticle interactions in aqueous solutions have been studied extensively and are modeled using classical electrical double layer theory $y^{5,6}$. Most waste particles have a positive surface charge at $\mathrm{pH}$ values below, have a negative surface charge above, and are neutral at the $\mathrm{pH}$ called the isoelectric point $^{7}$. Particles of like charge repel each other, producing dispersed suspensions that may not settle, and could pose serious separation, fouling, and contamination problems during processing of the low level waste stream. Particles aggregate if they have opposite charges, no charge or even the same charge provided that the ionic strength of the solution is sufficiently high to collapse the electrical double layer and allow van der Waals attractions to become dominant. Aggregates settle faster than primary particles, but pack less efficiently during sedimentation. Aggregation can also lead to much higher slurry viscosities at a given solids loading. 
Zeta potential is the potential of the particle at the surface of shear and is related to the electrophoretic mobility of the particle; therefore, a measurement of the zeta potential of a slurry as a function of $\mathrm{pH}$ will provide insight into the impact of $\mathrm{pH}$ on the sediment densities that would be obtained during settle-decant operations. Zeta potential measurement of colloidal dispersions at high salt concentrations is a new and unexplored scientific area with many reported departures from expected theory, including elimination of the isoelectric point and restabilization of colloidal particles with adsorbed surfactants.

Zeta potential is experimentally determined by measuring the motion of particles in solution under an applied electric field. Traditionally, these measurements are performed at low ionic concentrations due to experimental difficulties at high salt concentrations. A new method has been developed that permits the measurement of zeta potential at high salt concentrations. These measurements are still problematic and require attention to establishing the proper experimental conditions (voltage, frequency, and sample count rate) and expertise combined with common sense in interpreting the results. The high conductivity of the concentrated salt solutions limit the voltage and current that can be applied to the solution while still imparting movement of the particles due to the applied electric field. If too high a voltage is applied, water is broken down to hydrogen and oxygen at the anode and cathode respectively. If too high a current is applied, the sample is heated and fluid-flow gradients are created that disturb the measurement of particle motion.

Once the surface charge is determined, the net interaction between surfaces can be calculated as a function of $\mathrm{pH}$ and salt content to estimate regimes in which dispersion or agglomeration should occur. In the high $\mathrm{pH}$ regime maintained in most tanks, major tank waste constituents such as boehmite should all have negatively charged surfaces; however, extensive agglomeration is still expected due to the high salt content (1 to $5 \mathrm{M} \mathrm{NaNO}_{3}$ ) in Hanford tank solutions. 
Most simulants behave as expected based on measured interaction potentials. Submicron $(0.05 \mu \mathrm{m})$ boehmite is completely dispersed in dilute salt suspensions at $\mathrm{pH} 4$. At the isoelectric point of boehmite ( $\mathrm{pH}$ 9), light scattering measurements indicate that $70 \mu \mathrm{m}$ agglomerates, containing up to ten million primary particles, are present. In high $\mathrm{pH}$, high salt content (1 to 5 M) solutions representative of tank wastes, smaller $(1.5 \mu \mathrm{m})$ agglomerates prevail, suggesting that interparticle interactions are weaker here than at the isoelectric point.

The agglomerate size in simulated tank waste solutions increases modestly with primary particle size; however, the number of primary particles per aggregate decreases dramatically. For $1.3 \mu \mathrm{m}$ gibbsite, there are fewer than ten primary particles per $3 \mu \mathrm{m}$ agglomerate, compared with the 2,000 primary particles in a $1.5 \mu \mathrm{m}$ boehmite aggregate. Primary particles large than $10 \mu \mathrm{m}$ do not agglomerate in tank waste solutions.

Most simulated wastes form "soft" agglomerates that can be redispersed by changing the $\mathrm{pH}$ or lowering the salt content. However, if there is strong chemical bonding or precipitation at interparticle contacts, particles can be fused together to form "hard" agglomerates. For example, although aged $\mathrm{Fe}(\mathrm{OH})_{3}$ suspensions contain small $(0.05 \mu \mathrm{m})$ primary particles, $1.5 \mu \mathrm{m}$ agglomerates are always observed regardless of solution $\mathrm{pH}$, salt content, or agitation conditions. TEM analyses show that primary particles in aged $\mathrm{Fe}(\mathrm{OH})_{3}$ agglomerates all have the same crystalline orientation. The amorphous particles in fresh precipitates fuse during crystallization to form "single crystal" agglomerates.

\section{Agglomerate Structures and Fractal Geometry}

The properties of agglomerated sludges are dominated by the properties of the agglomerates, which are fractal objects whose mass scales as $\mathrm{R}^{\mathrm{D}}$, where $\mathrm{R}$ is the agglomerate size and $\mathrm{D}$ is the fractal dimension. For a diffusion-limited aggregate (where primary particles diffuse to a growing cluster, stick, and do not undergo further rearrangements), $\mathrm{D}=1.8 ; \mathrm{D}=3.0$ for a 
dense three-dimensional object ${ }^{8}$. Fractal agglomerates can have an enormous impact on slurry properties because they have lower densities and occupy much more space than dense particles at the same solids loading. The solids loading within an individual agglomerate, $\Phi \mathrm{a}$, is given by the expression $\Phi \mathrm{a}=(\mathrm{R} / \mathrm{r})^{\mathrm{D}-3}$, where $\mathrm{r}$ is the primary particle size. As shown in Figure 2, $\Phi$ a can vary over three orders of magnitude depending on the ratio of the agglomerate size to the primary particle size and the fractal dimension.

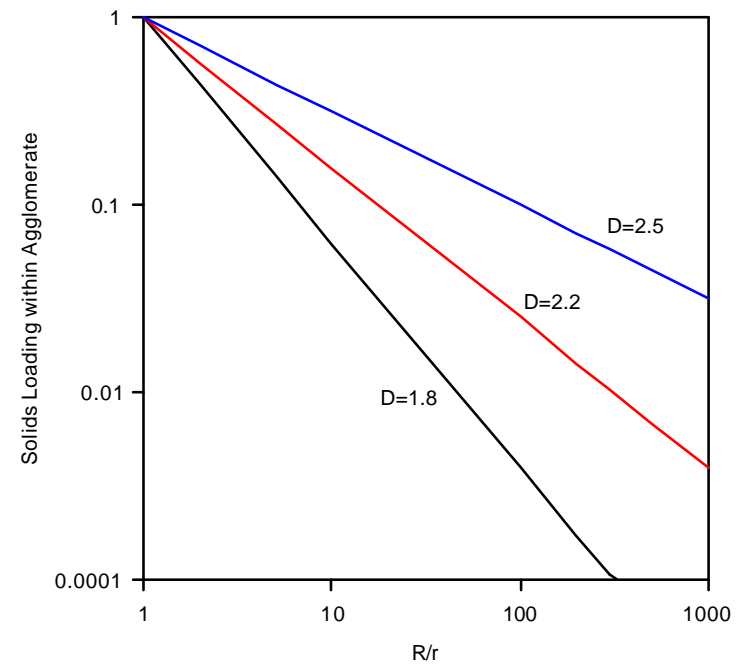

Figure 2. Solids Loading Within Fractal Agglomerates as a Function of R/r and D

Solids loadings within an agglomerate are smaller when $\mathrm{R} / \mathrm{r}$ is large or $\mathrm{D}$ is small. For $\mathrm{D}$ $=1.8$, boehmite agglomerates (with $\mathrm{r}=0.05 \mu \mathrm{m}$ and $\mathrm{R}=1.5 \mu \mathrm{m})$ pack much less efficiently $(\Phi \mathrm{a}$ $=1.7 \mathrm{vol} \%)$ than the $3.0 \mu \mathrm{m}$ agglomerates of $1.3 \mu \mathrm{m}$ gibbsite $(\Phi \mathrm{a}=50 \mathrm{vol} \%)$. The ability of submicron particles to form low-density agglomerates is one reason why submicron particles are of the greatest concern for the processing of tank wastes.

Quantitative models for slurry properties must account for the fact that fractal agglomerates tend to have fragile structures that can be deformed and rearranged. Internal rearrangement are reflected in static light scattering results that suggest that boehmite agglomerates are denser than diffusion-limited aggregates $(\mathrm{D}=2.04$ instead of 1.8). Light and $\mathrm{X}$ - 
ray scattering results on silica suspensions indicate that $\mathrm{D}=1.8$ when particles are strongly attracted to each other, while $\mathrm{D}=2.1$ when weaker interparticle interactions prevail (reactionlimited aggregation $)^{9,10,11}$. The $\mathrm{D}=1.8$ clusters eventually restructure to yield $\mathrm{D}=2.1$. For purposes of modeling both simulated and actual wastes, it is assumed that $\mathrm{D}=2.2$, which corresponds to the theoretical rearranged reaction-limited case ${ }^{12}$.

\section{Impact of Agglomerate Structures on Rheological and Physical Properties}

Fractal agglomerates can be disrupted as well as rearranged in a shear field. The fragile nature of aggregates can hamper attempts to determine "particle sizes" in actual sludges, because particle size measurements detect agglomerate size distributions that can be highly sensitive to sample preparation and analysis techniques. As shown in Figure 3,10 $\mu \mathrm{m}$ agglomerates in a tank waste simulant containing submicron $\mathrm{AlOOH}, \mathrm{Al}(\mathrm{OH})_{3}, \mathrm{Fe}(\mathrm{OH})_{3}$ and $\mathrm{SiO}_{2}$ particles are reduced in size to $2 \mu \mathrm{m}$ when pumped through a recirculation system in the particle size analyzer.

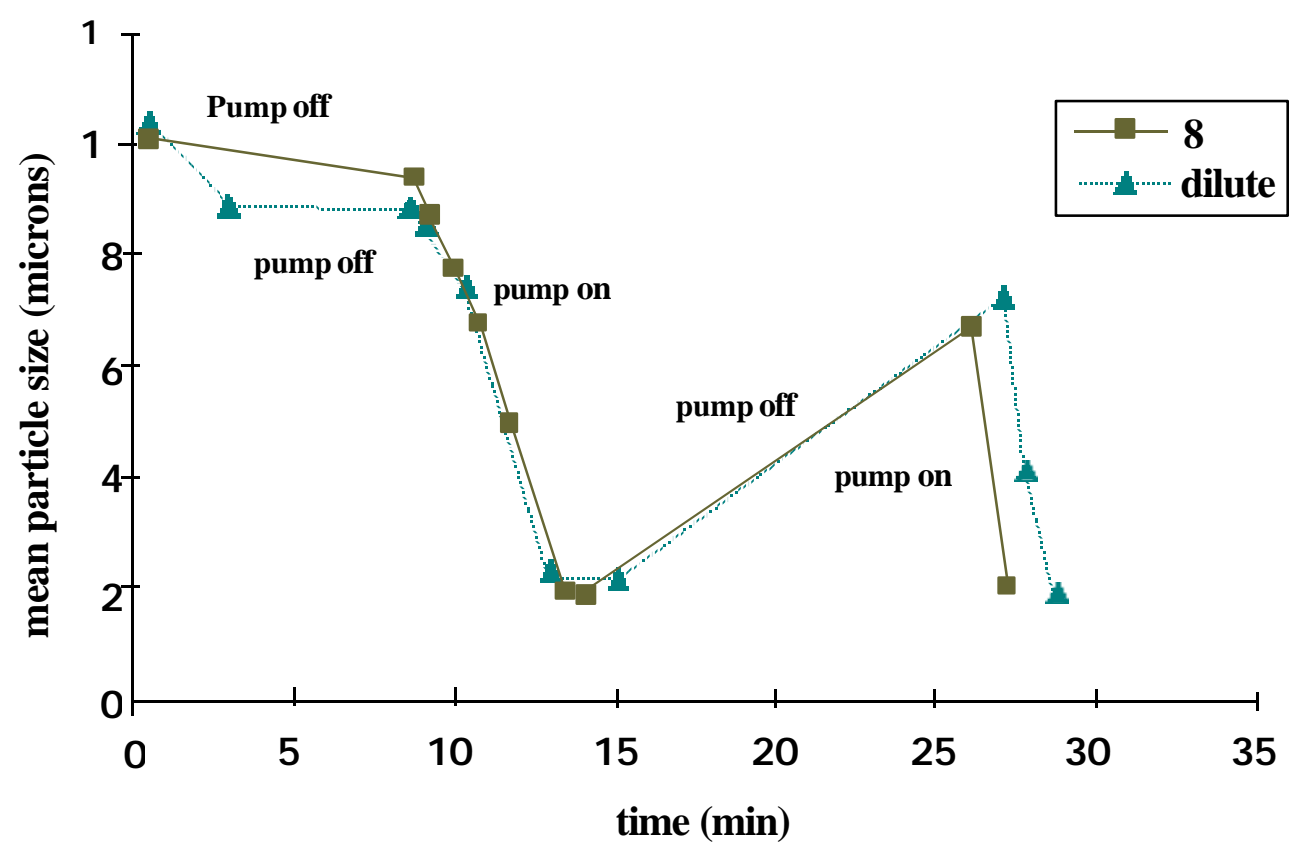

Figure 3. Agglomerate size during pumping as a function of time. 
Models for the break-up of flocs in moving fluids suggest that the stress dependence for the steady-state floc size is of the form ${ }^{13}$ :

$$
R=b \gamma^{(D-1) / 2 p(D-3)}
$$

where $\gamma$ is the shear rate $\left(\sec ^{-1}\right)$, be is a constant, $\mathrm{p}$ is a constant inversely proportional to the shear strength of the agglomerate, and where the moduli and critical stress leading to agglomerate rupture vary with volume faction as $\Phi^{\mathrm{q}}$. For $\mathrm{D}=2.2, \mathrm{q}=4.5$ (a typical value), and $\mathrm{R}=\mathrm{b} \mathrm{\gamma}^{-0.32}$, increasing the shear rate by 100 reduces the size of a $10 \mu \mathrm{m}$ agglomerate to $2.3 \mu \mathrm{m}$. If irreversible, this reduction would decrease the effective volume occupied by agglomerates by a factor of three, resulting in lower slurry viscosities and higher sediment densities.

The viscosity of colloidal suspensions depends on the size and shape of the suspended agglomerates and the solids loading. At a fixed shear rate, suspensions of submicron particles exhibit a viscosity that is also highly dependent on solution $\mathrm{pH}$ and salt content, consistent with predictions based on interaction potentials. For $0.05 \mu \mathrm{m}$ boehmite in a $0.01 \mathrm{M} \mathrm{NaNO}_{3}$ solution, individual primary particles are non-interacting and are not agglomerated at $\mathrm{pH} 3$. Viscosity measurements on boehmite suspensions at $\mathrm{pH} 3$ and up to 10 volume percent solids have low viscosities $(<5 \mathrm{cP})$ and behave like Newtonian liquids. Near the isoelectric point (where particles are heavily agglomerated) the viscosity of agglomerated boehmite suspensions is in sharp contrast to the behavior observed at $\mathrm{pH} 3$. The viscosity of a 10 volume percent suspension at $\mathrm{pH} 10$ and $0.01 \mathrm{M} \mathrm{NaNO}_{3}$ exceeds $10,000 \mathrm{cP}$ at low shear rates (below $20 \mathrm{~s}^{-1}$ ). The agglomerated slurries are non-Newtonian shear-thinning liquids. At higher salt concentrations (1 $\mathrm{M} \mathrm{NaNO}_{3}$ ), the agglomerated slurries exhibit non-Newtonian shear-thinning behavior over the entire $\mathrm{pH}$ range measured ( $\mathrm{pH} 2$ to 14). Although maxima in the viscosity are still seen at the isoelectric point and at high and low $\mathrm{pH}$, the viscosity is high at all $\mathrm{pH}$ values. The viscosity of 
10,6 , and 3 volume percent boehmite suspensions in $1 \mathrm{M} \mathrm{NaNO}_{3}$ at a shear rate of $11.5 \mathrm{~s}^{-1}$ are plotted as a function of $\mathrm{pH}$ in Figure 4.

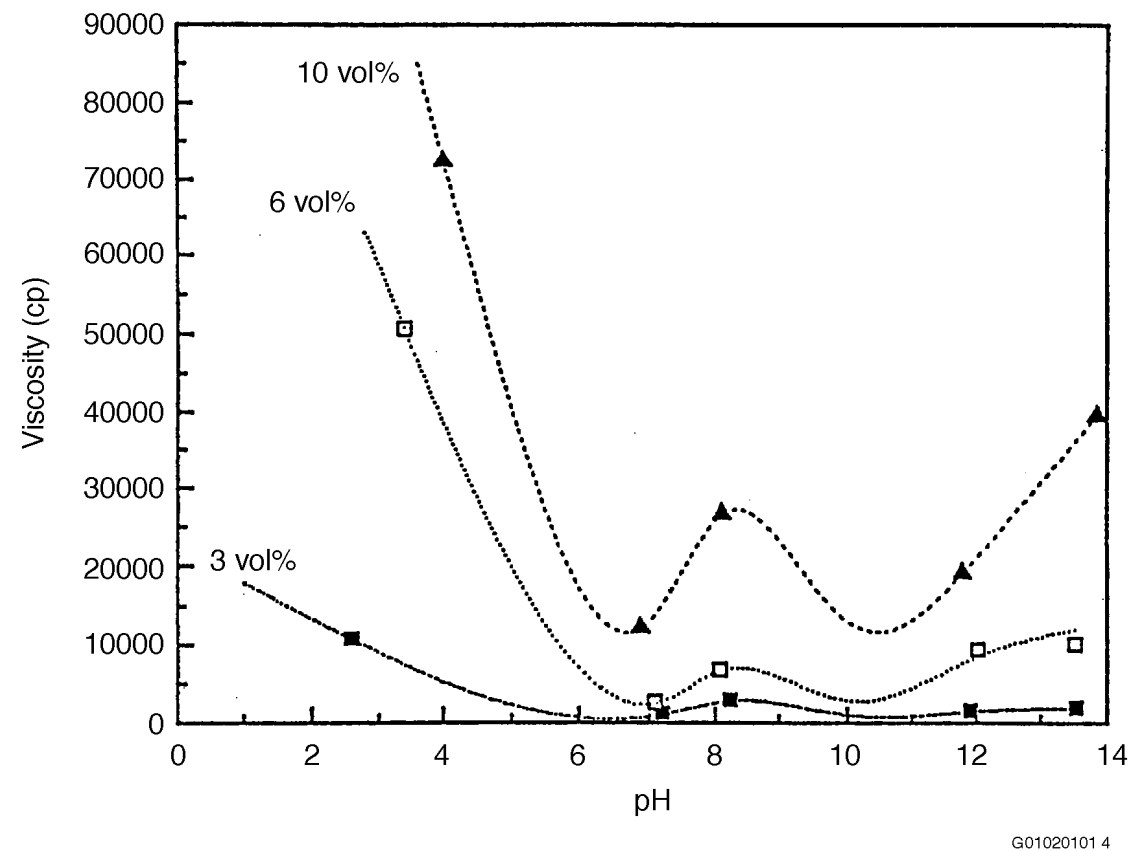

Figure 4. Viscosity of boehmite in $1 \mathrm{M} \mathrm{NaNO}_{3}$ as a function of $\mathrm{pH}$ and solids loading

Dispersed suspensions exhibit Newtonian behavior, where the viscosity is independent of the shear rate. Below the percolation threshold, slurry viscosities are low, similar to the viscosity of the fluid phase. Viscosities increase with solids loadings as individual particles increasingly interfere with each other consistent with the Krieger-Dougherty equation for the viscosity of dispersions.

$$
\frac{\eta}{\eta_{0}}=\left[1-\left(\Phi / \Phi_{M}\right)\right]^{-[\eta] \Phi_{M}}
$$

where $\eta_{0}$ is the fluid viscosity ( $1 \mathrm{cP}$ for water), $\Phi_{\mathrm{M}}$ is the maximum packing density (63 vol\% for random packing of hard spheres), and $[\eta]$ is the intrinsic viscosity for a given particle. For 
dispersed boehmite, the viscosity results are consistent with $[\eta]=20$ (compared with 2.5 for spheres) reflecting the fact that boehmite particles are plates with a high aspect ratio (1:10). Slurries of non-interaction spheres can exhibit viscosities of less than $100 \mathrm{cP}$ at solids loadings as high as 50 vol $\%^{14}$, showing that low viscosities can be achieved at high solids loadings if dispersed particles are present.

Below the percolation threshold, the decrease in viscosity with increasing shear in agglomerated suspensions reflects the extent to which solution agitation disrupts large agglomerates to form smaller ones. Above the percolation threshold, the decrease in viscosity reflects the ease at which shear disrupts a continuous particulate network. At fixed solids loading for these surrogate systems, the shear stress $\tau$ is related to the shear strain rate $\gamma$ by the power law exponent $\mathrm{n}$ and the constant $\mathrm{K}$ in the empirical expression

$$
\tau=K \gamma^{n}
$$

For $0.05 \mu \mathrm{m}$ boehmite suspensions ( $1 \mathrm{vol} \%$ boehmite in $1 \mathrm{M} \mathrm{NaNO}_{3}$ and $1 \mathrm{M} \mathrm{NaOH}$ solution), $\mathrm{n}$ $=0.86$ and $\mathrm{K}=2.5 \mathrm{~Pa}-\mathrm{s}(2500 \mathrm{cP})$. At identical solids loadings, $\mathrm{K}$ and $\mathrm{n}$ decrease as the primary particle size increases. Viscosities increase dramatically at solids loading approaching the percolation threshold. Acicular particles such as boehmite exhibit larger values for $\mathrm{K}$ and $\mathrm{n}$ then do more spherical particles such as $\mathrm{Fe}(\mathrm{OH})_{3}$.

Rheological analysis has been obtained on samples from 17 single-shell and 10 doubleshell tanks. Many of these samples were processed to simulate the baseline processes proposed for ultimate disposal of these tank wastes. Rheological properties have also been measured on these process samples. Tank $\mathrm{C} 107$, dominated by large $(1 \mu \mathrm{m})$ primary particle s of $\mathrm{AlOOH}$, $\mathrm{FeOOH}$, and aluminosilicates, is expected to exhibit a lower viscosity than most other tanks examined to date via TEM. Results (K=100 mPa-s and $\mathrm{n}=1$ at a solids loading of $3.3 \mathrm{vol} \%)$ are consistent with $R=6 \mu \mathrm{m}$ compared with a measured value of $5 \mu \mathrm{m}$. The viscosity of $\mathrm{C}-107$ waste at $3.3 \mathrm{vol} \%$ is comparable to that of simulated wastes containing similar primary particles 
and solids loadings $(1.3 \mu \mathrm{m}$ gibbsite at 4 vol\%). The rheological behavior of C-107 is also nearly the same as that of $0.7 \mathrm{vol} \% \mathrm{Fe}(\mathrm{OH})_{3}$ or $0.3 \mathrm{vol} \%$ boehmite. These similarities illustrate that sludges of submicron particles are expected to become viscous at substantially lower solids loadings than C-107 sludge.

Sludge from tank SY-102 also contains large particles $(r=1$ to $1.5 \mu \mathrm{m}$ and $\mathrm{R}=5 \mu \mathrm{m})$. "As-received" sludge with a solids loading of 5 vol\% exhibits shear thinning behavior with $\mathrm{K}=$ $1600 \mathrm{mPa}-\mathrm{s}$ and $\mathrm{n}=1.0$. However, dilution of SY -102 sludge by only a factor of two yields a Newtonian fluid with a viscosity comparable to that of the supernatant liquid (1.2 $\mathrm{mPa}-\mathrm{s})$. This result shows how critically dependent the viscosity is on solids loading.

When agglomerates fill the solution and begin to contact each other (at a solids loading referred to as the percolation threshold or gel point $(\Phi g=0.17 \Phi \mathrm{a})$, slurry viscosities can increase by orders of magnitude. Sediment densities are usually not much greater than $\Phi \mathrm{g}$ because sedimentation rates are slow to negligible above the gel point. Work on this project has shown that fairly accurate values for $\Phi \mathrm{g}$ can be calculated for both single component slurries and actual tank wastes if $r, \mathrm{R}$, and $\mathrm{D}$ are determined experimentally.

Primary particle size distributions have been determined using transmission electron microscopy, and agglomerate size distributions have been estimated using static light scattering on dilute suspensions as described above. Direct measurements of the fractal dimension D have not been made, but based on literature studies on model systems, $\mathrm{D}=2.2$ has been used to model slurry properties (the theoretical value for a rearranged reaction-limited aggregate). Using experimental $\mathrm{r}$ and $\mathrm{R}$ values and $\mathrm{D}=2.2$, sediment densities have been predicted to within about $20 \%$ for single component systems as well as actual sludges, solids loadings at which slurry viscosities will exceed the desired maximum of around $100 \mathrm{cP}$ have been predicted to within about $30 \%$, and sedimentation velocities in settle-decant operations have been predicted to within a factor of around 5. In terms of general trends, the least tractable slurries are those containing 
the smallest primary particles (10 $\mathrm{nm}$ particles are common in actual tank sludges), the largest agglomerate sizes, and the smallest fractal dimensions. Such slurries can have viscosities in excess of $10,000 \mathrm{cP}$ at solids loadings as low as $1 \mathrm{vol} \%$, which corresponds to the lowest sediment densities. At the other extreme, slurries containing primary particles larger than 10 ìm can exhibit viscosities below $100 \mathrm{cP}$ even at $30 \mathrm{vol} \%$ and pack to form dense sediments having solids loadings that exceed $35 \mathrm{vol} \%$. Of the 20 or so distinct Hanford wastes examined to date, most exhibit gel points from 1-8 vol\%. For the finest sludges, dilution factors as high as 20 may be required to keep from plugging pipes and transfer lines with viscous colloidal gels, generating millions of gallons of additional waste requiring treatment and ultimate disposal.

For waste processing, engineers need to be able to predict conditions under which slurry viscosities can be maintained below values suitable for pumping. Unfortunately, quantitative predictions of viscosity vs. shear rate curves as a function of particle type, solids loading, and solution chemistry are beyond existing models; however, solids loadings at which viscosities will become large can be estimated by inserting spherical agglomerates with known $\Phi_{\mathrm{a}}$ into "hard sphere" models. The actual solids loading, $\Phi$, in the Krieger-Dougherty equation for the viscosity of dispersions is replaced by the effective solids loading for agglomerates $\left(\Phi_{\text {eff }}=\Phi / \Phi_{\mathrm{a}}\right)$. The Krieger-Dougherty equation for the viscosity of dispersions is assumed to be valid for solids loadings near or below the percolation threshold (i.e. for slurries containing individual agglomerates as opposed to continuous particulate networks). To estimate apparent viscosities at any shear rate, the viscosity calculated using the Krieger-Dougherty equation is assumed to correspond to that measured at a shear rate $1 \mathrm{~s}^{-1}$ where agglomerate structures are relatively stable. Viscosities at higher shear rates are estimated assuming a power law exponent $n=1$. Viscosity measurements on dilute slurries can be used to infer $\Phi$ a. viscosity and particle size analyses have both been performed to determine the validity of correlating viscosities with agglomerate structures. For most simulants, estimates for R caculated on the basis of slurry 
viscosities are within $50 \%$ of measured $\mathrm{R}$ values provided that solids loadings are low enough to keep slurry viscosities below $200 \mathrm{cP}$. The results indicate that agglomerated suspensions of submicron particles may require dilution to below $1 \mathrm{vol} \%$ to ensure viscosities that are sufficiently low for reliable transport.

\section{Interparticle Interactions: Impact on Sediment Densities}

One focus of this research has been on achieving an understanding of the relationships between interaction potentials and sediment densities in the high-salt, high-pH regime representative of most tank wastes. Suspensions of particles or agglomerates settle at a velocity that depends on particle sizes, agglomerate structures, and solids loadings. In dilute suspensions where particles do no encounter each other, the initial sedimentation rate $\left(\mathrm{V}_{0}\right)$ is calculated using Stokes' Law:

$$
V_{0}=\frac{2 r^{2} \Delta \rho g}{9 \mu}
$$

where $\mathrm{r}$ is the particle radius, $\Delta \rho$ is the density difference between the particle and the liquid, $\mathrm{g}$ is the acceleration due to gravity, and $\mu$ is the liquid viscosity. For dispersed systems sedimentation rates decrease by a factor of 100 for each factor of ten reduction in partic le radius. Submicron particles settle at a negligible rate in dispersed regime since Brownian motion overwhelms sedimentation. Such suspended "fines" are desired to inhibit sedimentation during retrieval and transfer processes but cause serious problems for settle-decant operations. For dispersed sludges, only those suspensions containing primary particles larger than $3 \mu \mathrm{m}$ settle quickly enough to meet existing in-tank sedimentation requirements.

Fortunately, in the high-salt, high-pH solutions representative of tank wastes, attractive interparticle forces prevail, and all simulated wastes agglomerate and undergo sedimentation. The fraction of fines remaining in supernatant liquids after sedimentation is usually less than 5\% indicating that essentially all primary particles are consumed in aggregates. For agglomerated 
systems, sedimentation rates can be estimated using Stokes' Law by replacing the particle radius with the agglomerate size $(\mathrm{R})$, correcting $\Delta \rho$ to reflect the net density (particles plus fluid) within the agglomerate, and by correcting for fluid flow around and through agglomerate structures.

Tank wastes are generally comprised of mixtures of primary particles. If mixed agglomerates do not form from these mixtures, properties can be predicted based on the volume occupied by individual agglomerate types. Fore example, the effective sediment volume, $\Phi_{\text {mix }}$, at the percolation threshold is given by:

$$
\Phi_{\text {mix }}=\frac{0.17 \Phi_{A} \Phi_{B}}{\left[x \Phi_{B}+(1-x) \Phi_{A}\right]}
$$

where $\mathrm{x}$ is the solid volume fraction of component $\mathrm{A},(1-\mathrm{x})$ is the solid volume fraction of component $\mathrm{B}, \Phi_{\mathrm{A}}$ is $\Phi_{\mathrm{a}}$ for component $\mathrm{A}, \Phi_{\mathrm{B}}$ is $\Phi_{\mathrm{a}}$ for component $\mathrm{B}$, and 0.17 is the volume fraction occupied by "spherical" agglomerates at the percolation threshold. The measured sediment densities for the gibbsite: $\mathrm{Fe}(\mathrm{OH})_{3}$ mixtures agree with the calculated densities based on the agglomerate structures of the pure end members. For such mixtures, the net sediment density is dominated by the low density agglomerates as long as the volume fraction of the low density component is appreciable.

Sediment densities may not follow the simple pattern denoted in the equation above if components $\mathrm{A}$ and $\mathrm{B}$ are allowed to disperse and then reagglomerate due to changes in $\mathrm{pH}$, salt content, or temperature. Heating or agitation of mixtures can result in an increase or decrease in sediment densities depending on the component ratio.

Settling rates are extremely sensitive to agglomerate structures and span over five orders of magnitude for apparent "particle sizes" of 1 to $100 \mu \mathrm{m}$. Our practical goal is to be able to predict and control sediment densities in basic salt solutions. This regime is also of significant scientific interest because interaction potentials in such solutions cannot be described using 
classical electrical double-layer theory (the double layers collapse in high ionic strength solutions).

Under tank waste conditions, unhindered settling rates for the simulants range from a low of $0.1 \mathrm{~cm} / \mathrm{hr}$ (boehmite in $0.01 \mathrm{M} \mathrm{NaOH}$ ) to as high as $35 \mathrm{~cm} / \mathrm{hr}$ (for $2.5 \mu \mathrm{m} \mathrm{FeOOH}$ ). Unhindered settling rates for agglomerated simulants are usually within a factor of two of rates caculated based on measured agglomerate sizes (assuming $\mathrm{D}=2.2$ ).

Agglomerates become concentrated as they settle, and settling rates decrease due to hydrodynamic interactions, osmotic pressure effects, and interparticle contact. At the percolation threshold, where a continuous particle network forms, settling rates become slow and “equilibrium" sediment structure form. In high-salt, high-pH solutions, $\Phi_{\mathrm{s}}$, the volume fraction occupied by particles within the "equilibrium" sediment, ranges from 20 vol\% for $7.5 \mu \mathrm{m}$ gibbsite to $0.5 \mathrm{vol} \%$ for $0.05 \mu \mathrm{m}$ boehmite.

The macroscopic physical properties for a particular colloidal particle gel depend on both the gel microstructure and the interparticle forces. One example of a gel property is the compressive yield stress, $\mathrm{P}_{\mathrm{y}}(\phi)$, which is a measure of the force required to compact a gel network to a specified volume fraction, $\phi$. The compressive yield stress controls both the final sediment height of a colloidal suspension and the rate at which the sediment compresses to reach that final height. A model has been developed to calculate the compressive yield stress as a function of gel microstructure and interparticle forces using the Brownian dynamics simulation method.

In this model, the initial particle network configuration was created using Brownian dynamics. A random distribution of noninteracting particles is formed using a series of Monte Carlo moves. Brownian motion then moves the individual particles or particle clusters until contact is made with another particle or cluster. The two are then combined to form a rigid cluster, which then has transla tional and rotational diffusion based on cluster size. This procedure continues until a continuous gel has been formed. The first series of three-dimensional colloidal 
gel models consisted of 10,000 particles and was created assuming diffusion limited aggregation. Gels were created for 2.0, 4.0, 6.0 and 8.0 vol\%. A sample gel configuration is shown in Figure 5.

Once a gel configuration has been created, the rigid bonds are replaced with an interaction potential, which consists of both a repulsive core potential and a surface-bonding interaction. The core potential is based on the distance between particle centers. The surfacebonding interaction prevents a connecting particle from freely moving around the circumference of its partner, giving the gel its rigidity. The specified potential well depth determines the surface interaction strength. When the surface-point to surface-point distance exceeds a specified value, the connection is broken. If two particles move within the cutoff distance, a new connection is formed.

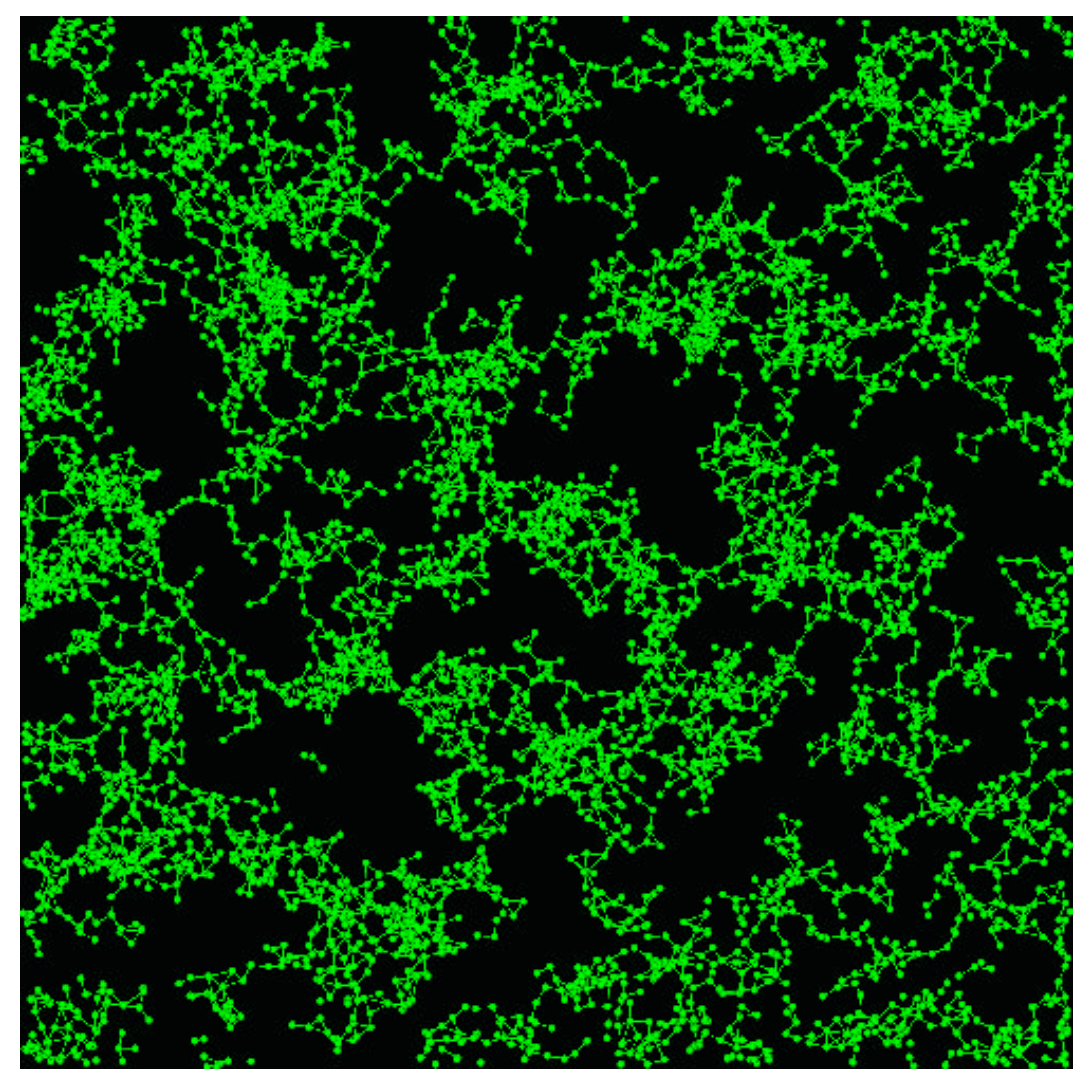

Figure 5. Initial Particle Gel Configuration from Brownian Dynamics Simulation 
The compressive yield stress as a function of volume fraction is determined by performing a compression simulation on the gel structure and calculating the resulting stress tensor. The compression simulation is performed using a repeating sequence of two stages, a compression stage and an equilibrium stage. During the compression stage, the scaling factor is gradually reduced in a linear fashion. The rate of reduction depends on a variety of factors, including the potential well depth and temperature. During this stage, interparticle connections are broken and new ones are created as the gel network structure changes to accommodate the reduction in volume. After a period of time, the scaling factor is held constant and the system is allowed to reach equilibrium. The approach to equilibrium is monitored using the calculated values of the stress tensor. Once the system has reached equilibrium, quantities such as the stress tensor and the coordination number are calculated for that volume fraction. This procedure is repeated until the volume fraction reaches a specified value. The calculated stress is then plotted as a function of volume fraction. Preliminary results have been obtained for the initial volume fractions listed for a single form of the interparticle potential.

This simulation methodology provides a direct connection between the microscopic interparticle interaction potential, which is not directly measurable, and the macroscopic gel property compressive yield stress, which can be obtained from sedimentation experiments. By varying the interparticle potential and comparing the change in the compressive yield stress with experimental results, we may be able to infer the effect of changes in solution chemistry on the interparticle potential.

Sedimentation experiments were performed at varying solids loadings, $\mathrm{pH}$, salt concentration, salt type, and applied pressure to determine the impact of chemical processing on the sediment densities that can be obtained during settle-decant processes. These results are also being compared with the models being developed. Based on these results, it is possible to extract values for the gel point and the compressive yield stress of the sediment (which is a measure of how deformable and compressible the sediment is.) Once these parameters are known, sediment 
densities can be predicted for a wide range of processing geometries, including extrapolation from lab-scale tests to sedimentation in a one-million-gallon tank.

Changes in salt content representative of sludge washing and leaching operations can change sediment volumes by as much as a factor of two, having an enormous impact on processing tank utilization and separation efficiencies. Sedimentation studies were conducted on 1.3 : m primary particles of gibbsite $\left(\mathrm{Al}(\mathrm{OH})_{3}\right)$ suspended in sodium nitrate solutions at different salt concentrations and $\mathrm{pH}$ values. At $\mathrm{pH} 4$ and $0.01 \mathrm{M} \mathrm{NaNO}_{3}$, the primary particles of gibbsite are dispersed. Because the particles are relatively large, they settle within a few days. The dispersed particles pack efficiently as they settle, yielding a sediment with a density of 50 vol\% (the theoretical maximum solids loading for packed spheres is 63 vol\%). Such a sediment would be ideal for maximizing the efficiency of solid-liquid separations. In contrast, the same gibbsite particles suspended in $0.1 \mathrm{M} \mathrm{NaNO}_{3}$ at $\mathrm{pH} 4$ yield a sediment density of only 4 vol\% solids (consistent with 6-7 $\mu \mathrm{m}$ fractal agglomerates each containing around 30 primary particles). This means that the agglomerated sludge occupies over 10 times more space and contains 24 times the volume of non-removable interstitial liquids than the sediment formed from the dispersed sludge, having an adverse impact on the efficiency of solids-liquids separations. As salt concentrations are increased still farther, to $5 \mathrm{M}$, sediment densities increase to $5.1 \mathrm{vol} \%$, suggesting that "short range" or "hydration" forces associated with adsorbed salt layers might be weakening the interactions between particles. High salt concentrations could also change sediment densities by changing agglomerate structures.

To investigate the role of adsorbed ions on interparticle interactions, systematic variations were made in the cations and anions present in dissolved salts to examine whether specific ions were more effective than others in weakening sediment structures. Gibbsite particles were suspended in aqueous solutions containing various salts $\left(\mathrm{NaNO}_{3}, \mathrm{NaCl}, \mathrm{CsCl}, \mathrm{LiCl}, \mathrm{Mg}\left(\mathrm{NO}_{3}\right)_{2}\right.$, $\mathrm{CaCl}_{2}$, and $\left.\mathrm{BaCl}_{2}\right)$ as a function of $\mathrm{pH}(\mathrm{pH} 4-14)$ and salt concentration $\left(10^{-2} \mathrm{M}-5 \mathrm{M}\right)$ (Figure 6). All salts tested promote sediment compression at concentrations above $1 \mathrm{M}$. While anion $\left(\mathrm{Cl}^{-}\right.$for 
$\left.\mathrm{NO}_{3}{ }^{-}\right)$and cation $\left(\mathrm{Li}^{+}\right.$or $\mathrm{Cs}^{+}$for $\mathrm{Na}^{+}$) substitutions have no apparent effect, salts of divalent cations $\left(\mathrm{Mg}^{2+}, \mathrm{Ca}^{2+}, \mathrm{Ba}^{2+}\right)$ all promote sediment compression. Most dramatic is the effect of $\mathrm{CaCl}_{2}$, which yields sediments having solids loading of over 15 vol\% (twice the particle density seen in $\mathrm{NaNO}_{3}$ solutions). The effect is not merely an ionic strength effect, because $\mathrm{BaCl}_{2}: \mathrm{NaCl}$ mixtures having the same ionic strength but different $\mathrm{Ba}$ :Na show greater compression as the $\mathrm{Ba}$ content is increased. The results suggest that heavily hydrated cations can act as "molecular ball bearings," allowing agglomerates to deform and compact. The results represent one example of how it may be possible to use chemical additives to control sludge behavior.

As is shown in Figure 7, $\mathrm{pH}$ has a significant impact on the sediment densities obtained during settle-decant operations. The lowest sediment density is observed near the isoelectric point of the particle with the sediment density increasing on either side of the isoelectric point.

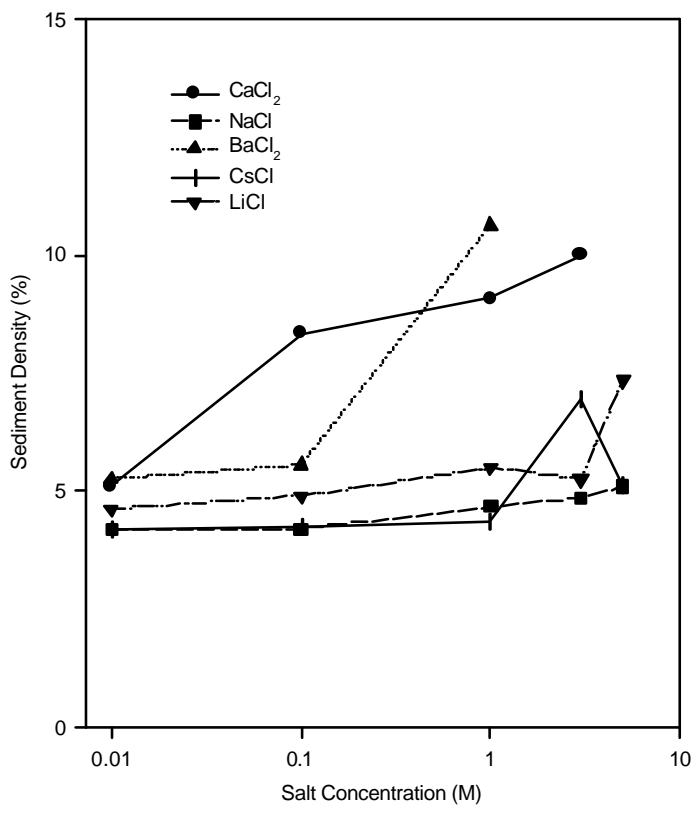

Figure 6. Impact of Salt Concentration and Salt Type on Sediment Density

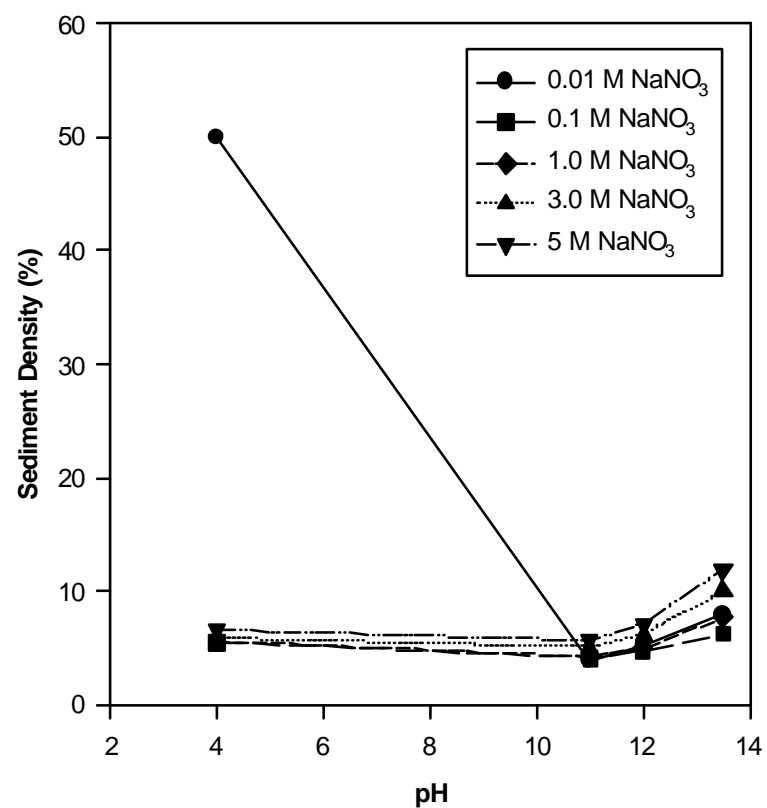

Figure 7. Impact of $\mathrm{pH}$ and Salt Content on Sediment Density

The zeta potential of alumina $(0.01 \mathrm{wt} \%)$ in water, $\mathrm{NaNO}_{3}$, and $\mathrm{LiCl}$ has been measured. Zeta potential measurements of alumina in water as a function of $\mathrm{pH}$ compared well with values 
reported in the literature. Zeta potential measurements of alumina in $\mathrm{NaNO}_{3}$, as a function of $\mathrm{pH}$, at higher salt concentrations were then undertaken. Measurements were made at 0.1, 1.0, 2.0 and 3.0 $\mathrm{M} \mathrm{NaNO}_{3}$.

Results suggest that at the lower salt concentration $(<2.0 \mathrm{M})$ double-layer theory is observed. This implies that the double layer has collapsed and that the system rapidly aggregates, forming a loose floc network of particles that exhibit a fast sedimentation time and a large sedimentation volume. Initial zeta potential measurements on alumina at $3.0 \mathrm{M} \mathrm{NaNO}_{3}$ suggest that the particle dispersion is restabilized and that the isolelectic point (point of zero charge) is not present. The particles exhibit a positive zeta potential over the entire $\mathrm{pH}$ range investigated. This implies that the particles do not aggregate into a loose floc network and will exhibit a smaller sedimentation volume. This has been confirmed by previous sedimentation results.

Heating or agitation of gibbsite:boehmite mixtures change the sediment densities as a function of the gibbsite:boehmite ratio. When boehmite is in excess, (gibbsite:boehmite =1:9), dispersion and reagglomeration processes "fluff-up" agglomerates (e.g. by decreasing D from 2.2 to 1.8 ), leading to lower sediment densities. When gibbsite is in excess, small boehmite primary particles can stick to and be consumed by the larger particles. Once the gibbsite surfaces are saturated (gibbsite:boehmite ratio of around 50:1), further boehmite additions decrease sediment densities and increase slurry viscosities as boehmite agglomerates begin to dominate. For gibbsite:boehmite mixtures, the boehmite coating acts like "ball bearings", increasing the compressibility and density of the sediment, and lowering slurry viscosities by ten-fold ${ }^{15}$. The lubrication effect of one particle type relative to another is also seen for mixtures of boehmite and apatite. Although boehmite and apatite have similar sizes, replacing only $20 \%$ of the boehmite with apatite can increase sediment densities by a factor of two and decrease viscosities by over a factor of 10. It is speculated that apatite disrupts the hydrogen bonding between boehmite particles, weakening short-range interactions and promoting sediment compression. 
Agglomerate structure correlations derived from simulant studies have been used to predict the behavior of actual tank wastes. Values of $\mathrm{r}$ and $\mathrm{R}$ used to evaluate the physical properties of actual wastes are based on the volume average primary particle and agglomerate sizes obtained via TEM and particle size analyzers, respectively, ignoring complications associated with multimodal suspensions. All agglomerates are assumed to have $\mathrm{D}=2.2$, as $\mathrm{D}$ has not yet been measured for radioactive wastes. Agglomerate structures and calculated properties for actual sludges are summarized in Table 1. Properties were measured during sludge caustic leaching $\left(2 \mathrm{M} \mathrm{NaOH}\right.$ at $\left.100^{\circ} \mathrm{C}\right)$ and washing $\left(0.01 \mathrm{M} \mathrm{NaOH} / 0.01 \mathrm{M} \mathrm{NaNO} 3\right.$ at $\left.50^{\circ} \mathrm{C}\right)$ from over fifteen different Hanford tanks ${ }^{16,17,18,19}$. For actual wastes, the standard initial solids loading of 1.7 vol\% was sometimes above the percolation threshold, leading to slow to negligible settling rates. Values of $\mathrm{V}_{0}$ and $\Phi_{\mathrm{s}}$ are only included for those tanks in which the initial solids loading was below $\Phi_{\mathrm{p}}$.

Measured sediment densities for actual sludges fall within the 1 to 8 vol\% range seen for simple simulants. For boehmite-rich wastes where submicron primary particles dominate (S-101, S-104, S-107, and SX-108), sediment densities (1.0 to 4.4 vol\%) are within $30 \%$ of values predicted based on agglomerate structures and are consistent with results obtained for the boehmite simulant. Tank S-101 and S-104 sludges, both with $\mathrm{r}=0.1 \mu \mathrm{m}, \mathrm{R}$ near $3 \mu \mathrm{m}$, and $\mathrm{R} / \mathrm{r}=$ 30, form less dense sediments than sludges in Tanks S-107 and SX-108 which have smaller R/r values ( 7 and 5 respectively). Multicomponent sludges with smaller primary particles or larger agglomerates (larger R/r) such as BX-107 and BY-110 also tend to have lower sludge densities. Sediment densities are 20 to $40 \%$ higher for sludges that settle from "wash" solutions $\left(0.01 \mathrm{M} \mathrm{NaNO}_{3} / 0.01 \mathrm{M} \mathrm{NaOH}\right)$ than from caustic leach solutions $(2 \mathrm{M} \mathrm{NaOH})$. These higher sediment densities could result from the break-up of large agglomerates into smaller agglomerates (leading to smaller $\mathrm{R} / \mathrm{r}$ values), the redistribtuion of fines onto the surfaces of larger particles as seen for the gibbsite:boehmite mixed primary particle simulants, increased sediment 
compressibility, or dissolution of the smallest primary particles within a given sludge. Results obtained from tank C-107 sludge suggest that agglomerate sizes do not change much during processing $(\mathrm{R}=3.0 \mu \mathrm{m}$ after both leaching and washing).

For actual wastes, Stokes' Law calculations using known $\mathrm{r}$ and $\mathrm{R}$ values provide a conservative estimate for determining sedimentation rates. Below the percolation threshold, initial sedimentation rates are either within a factor of two of Stokes' Law estimates (S-104, BX107, C-106, and C-107) or are much faster than expected (S-101, S-107, SX-108, BY-104, and T104) based on measured agglomerate sizes. Consistent with observations on simulants, it appears that agglomerates containing submicron primary particles sometimes aggregate during sedimentation to form larger flocs that settle more rapidly.

The implication of this work is that the colloidal properties of tank waste under high salt conditions (greater than $2.0 \mathrm{M}$ ) may not behave as expected. If colloidal tank waste is in fact restabilized under high salt conditions, particle size may be smaller than expected, sedimentation time and volume may be different than expected, and filtration properties may be different. 
Table 1. Properties of Tank Waste as a Function of Agglomerate Structures

\begin{tabular}{|c|c|c|c|c|c|c|c|c|c|c|}
\hline \multicolumn{4}{|c|}{ Size $(\mu \mathrm{m})$} & \multicolumn{3}{|c|}{ Solids Loading (vol\%) } & \multicolumn{2}{|c|}{ Settling Rate $(\mathrm{cm} / \mathrm{hr})$} & \multicolumn{2}{|c|}{ Agglomerate Size $(\mu \mathrm{m})$} \\
\hline Tank & $\mathbf{r}$ & $\mathbf{R}$ & $\mathbf{R} / \mathbf{r}$ & $\Phi_{i}$ & $\boldsymbol{\Phi}_{\mathrm{s}}$ & $\boldsymbol{\Phi}_{\mathrm{s}}$ (calc. $)$ & $\mathbf{V}$ & $\mathbf{V}_{\text {calc }}$ & $R_{\mathrm{s}}(\text { calc })^{1}$ & $\mathbf{R}_{\mathrm{v}}(\text { calc })^{2}$ \\
\hline S-101 & 0.1 & 3 & 30 & 0.3 & 1.0 & 0.7 & 30 & 0.4 & 3.6 & 146 \\
\hline S-104 & 0.1 & 3 & 30 & 0.8 & 1.1 & 0.7 & 0.2 & 0.4 & 3.2 & 1.6 \\
\hline S-107 & 0.1 & 0.7 & 7 & 1.7 & 4.4 & 3.4 & 1.1 & 0.1 & 0.5 & 6.0 \\
\hline SX-108 & 0.3 & 1.2 & 4 & 1.7 & 4.2 & 6.0 & 1.6 & 0.3 & 5.4 & 5.4 \\
\hline BX-107 & 1.3 & $12^{3}$ & 9.3 & 1.7 & 2.8 & 2.9 & 2.5 & 2.2 & 13 & 13 \\
\hline BY-104 & 0.3 & 1.5 & 5 & 1.7 & 5.7 & 4.4 & 11 & 0.4 & 1.1 & 28 \\
\hline BY-108 & 0.6 & 3 & 5 & 1.7 & 2.3 & 4.8 & 6.0 & 1.4 & 6.6 & 11 \\
\hline BY-110 & 0.1 & 1 & 10 & 1.7 & 3.8 & 2.7 & 1.6 & 0.1 & 0.6 & 12 \\
\hline C-106 & 1.0 & 5 & 5 & 1.7 & 6.8 & 4.8 & 4.0 & 3.5 & 2.9 & 5.6 \\
\hline C-107 & 1.0 & 5 & 5 & 1.7 & 7.7 & 6.8 & 4.1 & 3.5 & 2.4 & $5.8^{4}$ \\
\hline $\mathrm{T}-104$ & 1.3 & 6 & 4.6 & 1.7 & 6.0 & 5.1 & 2.5 & 6.5 & 4.3 & 2.6 \\
\hline
\end{tabular}

1. $\mathrm{R}_{\mathrm{S}}$ calculated is the agglomerate size $(\mathrm{R})$ calculated based on sediment density.

2. $\mathrm{Rv}$ calculated is the agglomerate size $(\mathrm{R})$ calculated based on sediment velocity.

3. Measured in glycerol.

4. Agglomerate size estimated from the slurry viscosity is $6 \mu \mathrm{m}$. 


\section{Steric and Electrosteric Stabilization of Colloids}

Work performed on this project at the University of Washington is being directed at understanding how organic molecules called steric stabilizers function in the high salt regime of tank wastes. Once the factors controlling steric stabilization at high ionic strength are understood, it may be possible to manipulate sludge behavior with low concentrations of such organic additives. The polymers used as steric stabilizers were BAB block copolymers of polyethylene oxide B blocks and polypropylene oxide A blocks. The B blocks are the stabilizing moiety, and the A blocks anchor the polymer to the laytex surface. The core particle is a polystyrene latex with sulfate functional groups that allow the polymers to anchor to the core particle.

The impacts of polymer molecular weight, salt concentration, and salt type on steric stabilization were investigated. Increasing the molecular weight of the polymer causes an increase in steric stabilization. A small increase in molecular weight from an 11-monomer-length polymer to a 13-monomer-length polymer, showed dramatic increases in stabilization of the particle. This increase may be due to ion binding of the salt in the longer polymer that is not possible in the shorter polymer. Results obtained from the 13-monomer-length polymer indicate that order of stabilization in high ionic strength solutions is $\mathrm{BaCl}_{2}>\mathrm{NaNO}_{3}, \mathrm{LiCl}, \mathrm{NaCl}, \mathrm{KCl}>$ $\mathrm{KSCN}, \mathrm{KNO}_{3}$. X-ray photoelectron spectroscopy (XPS) and RAMAN spectroscopy were performed on this same system in both $\mathrm{KSCN}$ and $\mathrm{BaCl}_{2}$ to understand the processes that cause stabilization to occur in $\mathrm{BaCl}_{2}$ and not in $\mathrm{KSCN}$ solutions. The results from these studies indicated that the Madelung shift (a constant representing the sum of the mutual potential coulombic attraction energy of all the ions in a lattice) correlates with the order in which the anions induce restabilization of these particles. It was also observed that $\mathrm{BaCl}_{2}$ tends to weaken the ether oxygen bonds in the polyethylene oxide more than the KSCN, but the conformation of the polyethylene oxide is the same in both the $\mathrm{KSCN}$ and $\mathrm{BaCl}_{2}$ solutions. 


\section{$\underline{\text { Relevance, Impact, and Technology Transfer }}$}

Capabilities developed and data generated through this EMSP project support several science and technology needs at the Hanford Site, Savannah River Site, Oak Ridge National Laboratory, and Idaho National Engineering and Environmental Laboratory. Hanford Site needs that are directly supported by this project include "Effect of Processing Gas Release, Waste Sedimentation, Rheological, and Other Behaviors (RL-WT049-S)", "Mechanisms of Line Plugging (RL-WT-040-S)", and "Process Models for Sludge Treatment (RL-WT038-S)". Other site needs that would be supported by the proposed program are listed in Table 2 below. Data obtained during this project can also provide a scientific basis for site technology needs. These needs are also listed in Table 2.

The Savannah River Site, Oak Ridge National Laboratory, and Idaho National Engineering and Environmental Laboratory have similar needs to those described at Hanford. Understanding the impact of colloidal agglomeration on waste processing will enhance the ability of these sites to remediate their wastes. Of particular interest to these sites are methods to improve solid/liquid separations and strategies to prevent transport line plugging.

Current processing concepts for the Hanford tank wastes assume that mixer pumping has no detrimental impacts on sedimentation and rheological properties of the waste slurries. These concepts also include solid/liquid separations (ultrafiltration) as part of the enhanced sludge washing. Processing these slurries including pumping, water washing, and caustic leaching significantly impacts colloidal agglomeration and the resulting rheological and sedimentation behavior of the slurry. Predicting the precipitation, agglomeration, and or gel formation of solids in a complex caustic suspension with high ionic strength requires a well-designed set of data from which model parameters can be determined. A fundamental understanding of colloidal agglomeration in slurries at high ionic strengths and in caustic solutions provides insight into the sedimentation and rheology of these waste slurries and the impact of processing on these properties. 
Table 2. Site Science and Technology Needs Supported by this Program

\begin{tabular}{|l|c|l|}
\hline & \multicolumn{2}{|c|}{ Science/Technology Need } \\
\hline Site & ID No. & \multicolumn{1}{|c|}{ Title } \\
\hline & & \\
\hline Hanford & RL-WT024 & Enhanced Sludge Washing \\
\hline & RL-WT060 & Better Waste Mixing Mobilization \\
\hline & RL-WT064 & $\begin{array}{l}\text { PHMC Retrieval and Closure--Hanford Past Practice Sluicing } \\
\text { Practices }\end{array}$ \\
\hline & RL-SNF06 & Sludge Treatment Process \\
\hline & RL-WT032-S & $\begin{array}{l}\text { Monitoring of Key Waste Physical Properties During Retrieval and } \\
\text { Transport }\end{array}$ \\
\hline & RL-WT037-S & Sludge Treatment \\
\hline & & \\
\hline & SROO-2039 & Methods to Unplug Waste Transfer Lines \\
\hline & SROO-2052 & $\begin{array}{l}\text { Aluminum Dissolution from HAW Sludge and its Impact on } \\
\text { Downstream Salt Processing }\end{array}$ \\
\hline Oak Ridge & ORTK-04 & Sludge Mixing and Slurry Transport \\
\hline & & \\
\hline Idaho & ID-2.1.65 & Treatment/Disposition of Removed Tank Sludge \\
\hline & & \\
\hline TFA & AR-WT-08-01 & Waste Chemistry and Physical Properties for Processing \\
\hline & S-WT-08-01 & Waste and Radionuclide Chemistry \\
\hline & & \\
\hline
\end{tabular}

Inter-area transport lines on the Hanford site have become plugged in the past due to sedimentation, phase changes, or reactions accompanied by precipitation or gel formation of these colloidal suspensions during transport. Information to predict and/or model pressure drop and critical transport velocity of these slurries and the effect of dilution, washing, or leaching on these properties is required to avoid plugging the transport lines. The data obtained from this program provides critical information regarding how processing parameters such as solids loading, $\mathrm{pH}$, salt concentrations, composition, suspending medium, and shear history influence critical properties of suspended sludges including viscosity and sedimentation. The analysis of this data leads to 
potential chemical and physical strategies for controlling and modifying agglomeration to optimize slurry properties for specific processing steps such as transport.

At the Idaho National Engineering and Environmental Laboratory, waste in the High Level Waste Tank Farm contains both settled and suspended solids. Treatment of these wastes may include methods to increase the density of these solids and decrease the volume of High Level Waste. These treatment methods can be improved by an understanding of the agglomeration behavior of the waste.

Concentrated sludges with up to 20 wt \% solids will be transported from Oak Ridge National Laboratory underground tanks through miles of pipeline to consolidated tanks and treatment facilities. The pipeline will be susceptible to plugging, if the slurries are not controlled to well-developed parameters. Colloidal agglomeration will effect this behavior significantly.

At the Savannah River Site about twenty-five percent of the sludge solids stored in the High Level Waste Tanks contains about $30 \mathrm{wt} \%$ aluminum in the form of gibbsite or boehmite. Both boehmite and gibbsite form colloidal suspensions whose rheological and sedimentation properties are very sensitive to ionic strength, $\mathrm{pH}$, and shear history. Efficient solid/liquid separations need to be developed to consistently control aluminum removal from these waste streams. An understanding of the colloidal behavior in boehmite and gibbsite systems will provide the scientific basis to optimize these solid/liquid separations. The Savannah River high level waste system also contains a network of transfer lines that may become blocked during transport. Changes in the composition and phases in the boehmite and gibbsite systems as a function of temperature, $\mathrm{pH}$, ionic strength, and shear will help to prevent plugged transport lines.

Information regarding agglomerate structures in tank sludges can be used in waste processing in either an "active" or "passive" mode. In the passive mode, engineers can define processing windows based on a knowledge of what agglomerates are present and how these agglomerates are expected to behave. Variables that define processing windows include solids loading, $\mathrm{pH}$, and the salt content of processing fluids. For Hanford tank waste processing scenarios, the 
diluents under consideration (water, basic solutions, aqueous solutions containing molar quantities of $\mathrm{NaNO}_{3}$, or basic solutions containing molar quantities of $\mathrm{NaNO}_{3}$ ) result in processing fluids within the high-salt, high-pH regime where agglomeration is expected to be extensive; therefore, the primary challenge of engineers will be to establish the maximum solids loading for various processing steps to minimize overall waste volumes.

Data on short-range interaction potential and their effect on agglomeration is critical in moving from the "passive" to the "active" regime of waste processing. In the "active" regime, sludge behavior is controlled via deliberate manipulation of agglomerate structures. "Active" strategies could include addition of dispersants prior to transport to minimize agglomeration and to keep slurry viscosities low. Once at central processing facilities, other chemicals could be added as flocculating agents to promote rapid and complete sedimentation. Any "active" processing on radioactive wastes must be performed with extreme care. Typical organic surfactants are not designed to function in the high-salt environments in tank wastes. In addition, organic compounds can undergo radiolysis and generate byproducts that may lead to processing or safety issues.

Results of this project suggest that it may be possible to either control species concentration in existing tanks or identify species that can be added at low concentrations to make handling of colloidal sludges more tractable. The ideal would be to optimize solution conditions to produce a finite, but small attraction between particles. This attraction would be sufficient to promote agglomeration, leading to rapid sedimentation, yet weak enough to be disrupted under low shear conditions, promoting low viscosities during pumping and high levels of sediment compaction.

If the effective viscosity of tank wastes must be kept low $(<100 \mathrm{cP})$ for pumping, solids loadings should not exceed $50 \%$ of the percolation threshold for any given sludge. The extent of dilution required to achieve a low viscosity fluid will depend on the ratio of the initial sediment density in the tank to the desired solids loading in the slurry which can be predicted if the agglomerate structures and sediment compressibility are known. Wastes with large primary 
particles and high compressive yield strength (such as Hanford tank SY-102) could require dilution factors as low as 2 , while wastes with highly compressible but low density agglomerates (such as boehmite), could require dilution factors as high as 20 . If submicron wastes requiring dilution factors of twenty are most common, waste volumes at Hanford could increase form 55 Mgal to over one billion gallons during processing. For tanks requiring undesirably high dilution factors, a less conservative approach might be to rely on high shear rates to keep viscosities low. For example, Hanford tank C-107 with an initial sediment density near $30 \mathrm{vol} \%$ and a desired slurry density for pumping of near 3 vol\% would normally require a sludge dilution factor of 10 . At a shear rate of $100 \mathrm{~s}^{-1}$, the desired slurry density for tank C-107 could be doubled to 6 vol\% resulting in a dilution factor of only 5. However, the risk of clogging transfer lines if shear rates dropped could be unacceptable. Decreasing the shear rate to $1 \mathrm{~s}-1$ would increase the apparent viscosity to $10,000 \mathrm{cP}$. Alternate schemes such as in-tank processing may need to be considered to avoid the risks of clogging pipes and/or creating huge waste volumes.

The high dilution levels required for pumping should ensure that initial solids loadings for sludges delivered to holding tanks for washing, leaching, or other treatments will be below the percolation threshold. Studies with both surrogates and actual wastes suggests that the "astransported" agglomerates should settle rapidly to yield sediments that are almost as dense as the materials stored in their native tanks. Sludge behavior during subsequent processing steps will be highly dependent on how processing conditions change agglomerate structures. Factors that could increase sediment densities include a reduction in agglomerate sizes, a decrease in fractal dimensions (agglomerate densification), and an increase in sediment compressibility. Conversely, sediment densities can decrease by a factor of two or more if dispersion and reagglomeration leads to the formation of larger and/or wispier agglomerates. All of the above factors are influenced by the interaction potential between the particles, which is influenced by solution and surface chemistry. 
The capabilities developed in this project have been used in obtaining more detailed physical properties on actual tank waste sludges and other radioactive waste samples such as K-Basin sludges. Extensive particle size distribution, sedimentation behavior, and particle density data have been obtained on samples from Hanford tanks AW-101, AN-107, and AN-105 using the equipment and knowledge obtained in this project. Significant processing issues of the K-Basin sludges have been resolved based on data obtained and understood because of the research efforts associated with this project.

\section{Project Productivity}

The project was on schedule and met most of its proposed goals. At the completion of the first fiscal year of effort, the Sandia National Laboratories scope of work was removed from this project and continued as an independent EMSP project. The results form the Sandia scope of work completed during the first fiscal year is reported in their final report; therefore, this work is not described in this report.

Difficulties in obtaining accurate data on representative tank waste surrogates on the Surface Force Apparatus (SFA) and the Small-Angle X-ray Scattering (SAXS) limited the data obtained on short-range hydration forces and fractal dimensions for tank waste slurries. These systems were developed and measurements of short-range hydration forces and fractal dimensions were made on other systems that were more compatible with these methods.

\section{Personnel Supported}

\section{Pacific Northwest National Laboratory}

Dr. Bruce C. Bunker

Chief Scientist

Materials Science Department

Gordon L. Graff

Senior Research Scientist

Materials Science Department

Dr. Keith D. Keefer

Staff Scientist

William R. Wiley Environmental Molecular Sciences Laboratory 
Dr. A. Scott Lea

Research Scientist

William R. Wiley Environmental Molecular Sciences Laboratory

Dr. Jun Liu

Staff Scientist

Materials Science Department

Dr. David R. Rector

Senior Research Scientist

Environmental Technology Division

Dr. Peter A. Smith

Senior Research Scientist

Environmental Technology Division

Dr. Joel M. Tingey

Project Manger

Environmental Technology Division

Dr. Jud W. Virden

Senior Development Engineer

Materials Science Department

\section{University of Washington}

Prof. John C. Berg

Rehnberg Professor of Chemical Engineering

Department of Chemical Engineering

Dr. V. Susan Stenkamp

Graduate Student

Department of Chemical Engineering

\section{Sandia National Laboratories}

Dr. James E. Martin

Nanostructures and Advanced Materials Chemistry

Douglas B. Adolf

Organic Materials

Dr. Gerald L. Gulley

Postdoctoral Fellow

Nanostructures and Advanced Materials Chemistry

Dr. Kimberly M. Hill

Postdoctoral Fellow

Nanostructures and Advanced Materials Chemistry 


\section{Publications}

Bunker BC, J Liu, DR Rector, GL Graff, PA Smith, PJ Bruinsma, L Song, XS Li, JD Virden, NG Colton, JR Philips, KD Keefer, and JM Tingey. 1999. "Fractal Colloidal Agglomerates in Nuclear Tank Wastes: Impact on Waste Properties and Processing" (accepted to Radioactive Waste Management in Environmental Restoration).

Hill KM, JE Martin, and DA Adolf. 1998. "Rheology of Colloidal Suspensions and Its Implication for Tank Waste Processing," Materials Research Society Symposium Proceedings, Spring 1998. San Francisco, California.

Stenkamp VS and JC Berg. 1997. "The Role of Long Tails in Steric Stabilization and Hydrodynamic Layer Thickness," Langmuir, $13,3827$.

Stenkamp VS and JC Berg, "Solvent Extraction and Raman Spectroscopy of Aqueous Polyethylene Oxide/Salt Solutions," To be published.

Stenkamp VS, PM McGuiggan, and JC Berg. 2000. "Restabilization of Electrosterically Stabilized Colloids in High Salt Media," Accepted Langmuir,

Tingey JM, BC Bunker, GL Graff, KD Keefer, AS Lea, DR Rector. 1999. "Colloidal Agglomerates in Tank Sludge and Their Impact on Waste Processing," Materials Research Society Symposium Proceedings, Vol. 556, Scientific Basis for Nuclear Waste Management XXII, David J Wronkiewicz and Joon H. Lee, Eds., 1315-1322.

"Colloidal Agglomerates in Tank Sludge: Impact on Waste Processing" in Science to Support DOE Site Cleanup: The Pacific Northwest National Laboratory Environmental Management Science Program Awards (Fiscal Year 1998 Mid-Year Progress Report). PNNL-11899 UC-721, Pacific Northwest National Laboratory, Richland, Washington, pp. 1.31-1.39, May 1998.

"Colloidal Agglomerates in Tank Sludge: Impact on Waste Processing" in Science to Support DOE Site Cleanup: The Pacific Northwest National Laboratory Environmental Management Science Program Awards (Fiscal Year 1999 Mid-Year Progress Report). PNNL-12208 UC-2000, Pacific Northwest National Laboratory, Richland, Washington, pp. 1.49-1.58, May 1999.

\section{$\underline{\text { Interactions }}$}

\section{Presentations}

K. M. Hill, J. E. Martin, and D. B. Adolf, "Rheology of Colloidal Suspensions and Its Implication for Tank Waste Processing," Materials Research Society Symposium, Spring 1998, San Francisco, California.

V.S. Stenkamp and J.C. Berg, "The Effect of Long Tails on Steric Stability," ACS 71st Colloid and Surface Science Symposium, June 1997.

V.S. Stenkamp and J.C. Berg, "Restabilization of Electrosterically Stabilized Colloids in High Salt Media," ACS 72nd Colloid and Surface Science Symposium, June 1998.

J. M. Tingey, B. C. Bunker, G. L. Graff, K. D. Keefer, A. S. Lea, and D. R. Rector, "Colloidal agglomerates in tank sludge and their impact on waste processing." Materials Research Society Fall Meeting, November 1998, Boston.

J. M. Tingey, P. R. Bredt, and R. Shekarriz, "Rheology and Settling Behavior of Hanford Tank Wastes and the Resulting Process Streams." Rheology in Mineral Industry II, March 1999, Kahuku, Oahu, Hawaii. 
J. M. Tingey, G. L. Graff, and D. R. Rector. "Effect of Colloidal Aggregation on Sedimentation and Rheology in Highly Basic, High Ionic Strength Salt Solutions.” Rheology in Mineral Industry II, March 1999, Kahuku, Oahu, Hawaii.

\section{Consultative and Advisory Functions}

1) British Nuclear Fuels, Ltd., Inc.

Eugene V. Morrey, Battelle Project Manager

January 1999 to October 1999

Measurement of rheological properties, particle size distribution, and physical properties and analysis of the resulting data was performed on samples from Hanford tanks AW-101 and AN107. These analysis are to be used in designing the Waste Vitrification Plant processes at the Hanford Site.

K. P. Brooks, P. R. Bredt, G. R. golcar, S. A. Hartley, M. W. Urie, J. M. Tingey, K. G. Rappe, and L. K. Jagoda, "Ultrafiltration and Characterization of AW-101 Supernatant and Entrained Solids”, PNWD-3000, Battelle Memorial Institute, Richland, Washington, October 1999.

Fluor Daniel Hanford, Inc.

Kurt L. Silvers, PNNL Project Manager

October 1997 to June 1999

Rheological properties, particle size distribution, and physical properties of sludge from Hanford $\mathrm{K}$ Basins were measured, and the resulting data was analyzed to determine the most efficient methods to process the K Basin sludges.

B. J. Makenas, T. L. Welsh, R. B. Baker, G. R. Golcar, P. R. Bredt, A. J. Schmidt, and J. M. Tingey, "Analysis of Sludge from Hanford K West Basin Canisters", HNF-1728 UC2070, Flour Daniel Hanford, Inc., Richland, Washington, February 1998.

A. J. Schmidt, K. L. Silvers, P. R. Bredt, C. H. Dele gard, E. W. Hoppe, J. M. Tingey, A. H. Zacher, T. L. Welsh, R. B. Baker, and B. J. Makenas, "Supplementary Information on K Basin Sludges”, HNF-2367 UC-2070, Flour Daniel Hanford, Inc., Richland, Washington, February 1999.

T. L. Welsh, P. R. Bredt, G. R. Golcar, A. J. Schmidt, K. L. Silvers, J. M. Tingey, A. H. Zacher, R. B. Baker, and B. J. Makenas, "Analysis of Internal Sludge and Cladding Coatings from NReactor Fuel Stored in Hanford K Basins", HNF-3589 UC-2070, Flour Daniel Hanford, Inc., Richland, Washington, June 1999.

3) CH2M Hill Hanford Group Yasuo Onishi, PNNL Project Manager October 1997 to September 1998

Determine the physical properties of waste in Hanford tank AN-105 and provide the data necessary to accurately predict the processes required for retrieval of this waste. The physical properties to be determined include density, particle size distribution, particle shape and morphology, viscosity, compressive yield strength, and settling behavior. 


\section{Transitions}

The knowledge developed and the capabilities obtained in this project have been used in obtaining more detailed physical properties on actual tank waste sludges and other radioactive waste samples. An understanding of colloidal behavior in tank wastes has been and will continue to have an impact on tank waste processing and retrieval and transport of tank waste slurries. Extensive particle size distribution, sedimentation behavior, and particle density data have been obtained on samples from Hanford tanks. The tank waste retrieval proje cts continues to utilize the expertise developed by staff at PNNL to develop methods for accurate determination of physical and rheological properties and analyze the data obtained by these methods.

Currently, Numatec Hanford Corporation has funded a joint effort between the 222-S Laboratory on the Hanford Site and PNNL to determine a method to accurately measure particle size distribution of tank waste samples. The expertise developed through this project should continue to support the Hanford Site on waste remediation issues.

\section{Patents}

None

\section{Future Work}

There continues to be insufficient data available to predict short-range and double layer forces controlling particle interactions in the high-salt regime. The lack of hard data on shortrange interaction potentials and their effect on agglomeration is hampering efforts to predict how to control sludge behavior via deliberate manipulation of agglomerate structures. Continued effort should be made to accurately determine short-range and double layer forces and measure fractal dimensions in surrogates representative of tank waste samples.

Agglomeration and deagglomeration processes under flowing conditions, changes in the molecular composition and physical properties under flowing conditions, and the rheological behavior of colloidal systems in viscoelastic fluids need to be better understood and correlated 
with colloidal models. These results need to be compared with similar studies performed on actual tank wastes. Methods to manipulate the agglomerate structures to optimize tank waste processing conditions should be explored.

A link between basic colloids science and rheology to macroscopic properties of interest to process design engineers need to be established to provide a technically defensible strategy for handling existing waste-related problems.

\section{Literature Cited}

1 J. E. Martin and J. Odinek, J. Colloid Int. Sci., $\underline{154}, 461$ (1992).

2 D. R. Rector and B. C. Bunker, Effect of Colloidal Aggregation on the Sedimentation and Rheological Properties of Tank Waste, PNL-10761, Pacific Northwest National Laboratory, Richland, Washington, 1995.

3 J. Liu, L. R. Pederson, and L. Q. Wang, Solid-Phase Characterization in Flammable-Gas Tank Sludges by Electron Microscopy, PNL-10723 UC-510, Pacific Northwest National Laboratory, Richland, Washington, August 1995.

4 R. L. McKay, TWRS Retrieval Technology Project Slurry Transport-Plugging Investigation, letter report to Westinghouse Hanford Company, August 1993.

5 J. Israelachvili, Intermolecular and Surface Forces, Academic Press, New York, 1992.

6 R. G. Horn, J. Am. Ceram. Soc., 73, 1117 (1990).

7 G. A. Parks, Chem. Rev., $\underline{65}, 117$ (1965).

8 D. A. Weitz, J. S. Huang, M. Y. Lin, and J. Sung, Phys. Rev. Lett., $\underline{54}$, 1416 (1985).

9 D. W. Schaefer, J. E. Martin, P. Wiltzius and D. S. Cannell, Phys. Rev. Lett., 52, 2371 (1984).

10 C. Aubert and D. S. Cannell, Phys. Rev. Lett., $\underline{56}, 738$ (1986).

11 D. W. Schaefer and K. D. Keefer, Phys. Rev. Lett., $\underline{56}, 2199$ (1986).

12 C. J. Brinker and G. W. Scherer, Sol-Gel Science: They Physics and Chemistry of Sol-Gel Processing, Chapter 5, Academic Press, San Diego, 1990.

13 R. S. Sontagg and W. B. Russel, J. Colloid Interface Sci., 115, 378 (1987).

14 D. A. R. Jones, B. Leary, and D. V. Boger, J. Colloid Interface Sci, 147, 479 (1991).

15 P. J. Bruinsma, Y. Wang, X. S. Li, J. Liu, P. A. Smith, and B. C. Bunker, J. Colloid Interface Sci., 192, 16 (1997). 
${ }^{16}$ G. J. Lumetta, B. M. Rapko, M. J. Wagner, J. Liu, and Y. L. Chen, Washing and Caustic Leaching of Hanford Tank Sludges: Results of FY 1996 Studies, PNNL-11278 UC-721, Pacific Northwest National Laboratory, Richland, Washington, August 1996.

${ }^{17}$ G. J. Lumetta, I. E. Burgeson, M. J. Wagner, J. Liu, and Y. L. Chen, Washing and Caustic Leaching of Hanford Tank Sludges: Results of FY 1997 Studies, PNNL-11636 UC-721, Pacific Northwest National Laboratory, Richland, Washington, June 1997.

${ }^{18}$ K. P. Brooks, J. R. Phillips, R. L. Meyers, K. G. Rappe, D. R. Rector, and P. A. Smith, Sludge Pretreatment Studies Using Hanford Tank C-107, Letter Report to Westinghouse Hanford Company, September 1996.

${ }^{19}$ G. J. Lumetta, B. M. Rapko, J. Liu, D. J. Temer, and R. D. Hunt, Washing and Caustic Leaching of Hanford Tank Sludges: Results of FY 1998 Studies, PNNL-12026 UC-721, Pacific Northwest National Laboratory, Richland, Washington, December 1998. 